\title{
Effects of Structural Congestion and Surrounding Obstacles on the Overpressure Loads in Explosions: Experiment and CFD Simulations
}

\author{
Myeong Hyeon Bae ${ }^{1}$ and Jeom Kee Paik ${ }^{1,2,3^{*}}$ \\ ${ }^{1}$ Department of Naval Architecture and Ocean Engineering, Pusan National University, Busan 46241, \\ Korea \\ ${ }^{2}$ The Korea Ship and Offshore Research Institute (The Lloyd's Register Foundation Research Centre \\ of Excellence), Pusan National University, Busan 46241, Korea \\ ${ }^{3}$ Department of Mechanical Engineering, University College London, Torrington Place, London \\ WC1E 7JE, UK \\ *Corresponding author. Tel.: +82515102429. \\ E-mail address: jeompaik@pusan.ac.kr (J.K. Paik).
}

\begin{abstract}
An experimental and numerical study was undertaken to identify the characteristics of overpressure loads in offshore platform models subject to hydrocarbon explosions, with a focus on the structural congestion and surrounding obstacles. A large-scale (one-half) test model of a FLNG (liquefied natural gas floating production storage and offloading unit) topside structure was used for the experiment. Computational fluid dynamics (CFD) were used to calculate the overpressure loads in explosions with varying degrees of structural congestion. The overpressure loads tended to be more significant with the increase in structural congestion because the ventilation of exploded gas was retarded due to the obstacles presented by congested structural elements. Also, the overpressure loads with the surrounding structures are much larger than those without them. Details about the test database are documented to provide a useful reference for other researchers to validate numerical and theoretical methods.
\end{abstract}

Keywords: Hydrocarbon explosion, overpressure loads, structural congestion, surrounding structures, computational fluid dynamics simulation

\section{Introduction}

Although offshore platforms are likely to be subjected to various types of accidents, a majority of accidents are related to hydrocarbon explosions and fires (Christou and Konstantinidou 2012). Explosion is a phenomenon in which hydrocarbons such as oil and gas explode through ignition when combined with an oxidiser, e.g., oxygen or air. Combustion takes place when temperatures rise to a critical point at which hydrocarbon molecules react spontaneously with an oxidiser, causing a blast or a rapid increase in pressure. Fire is a phenomenon in which a combustible vapour or gas combines with an oxidiser in a combustion process that manifests in the evolution of light, heat and flame (Paik et al. 2012). 
As illustrated in Figures 1 and 2, the identification of overpressure loads and elevated temperatures is the primary task for the quantitative risk assessment and management associated with explosions and fires, respectively (Paik et al. 2013 and 2014).

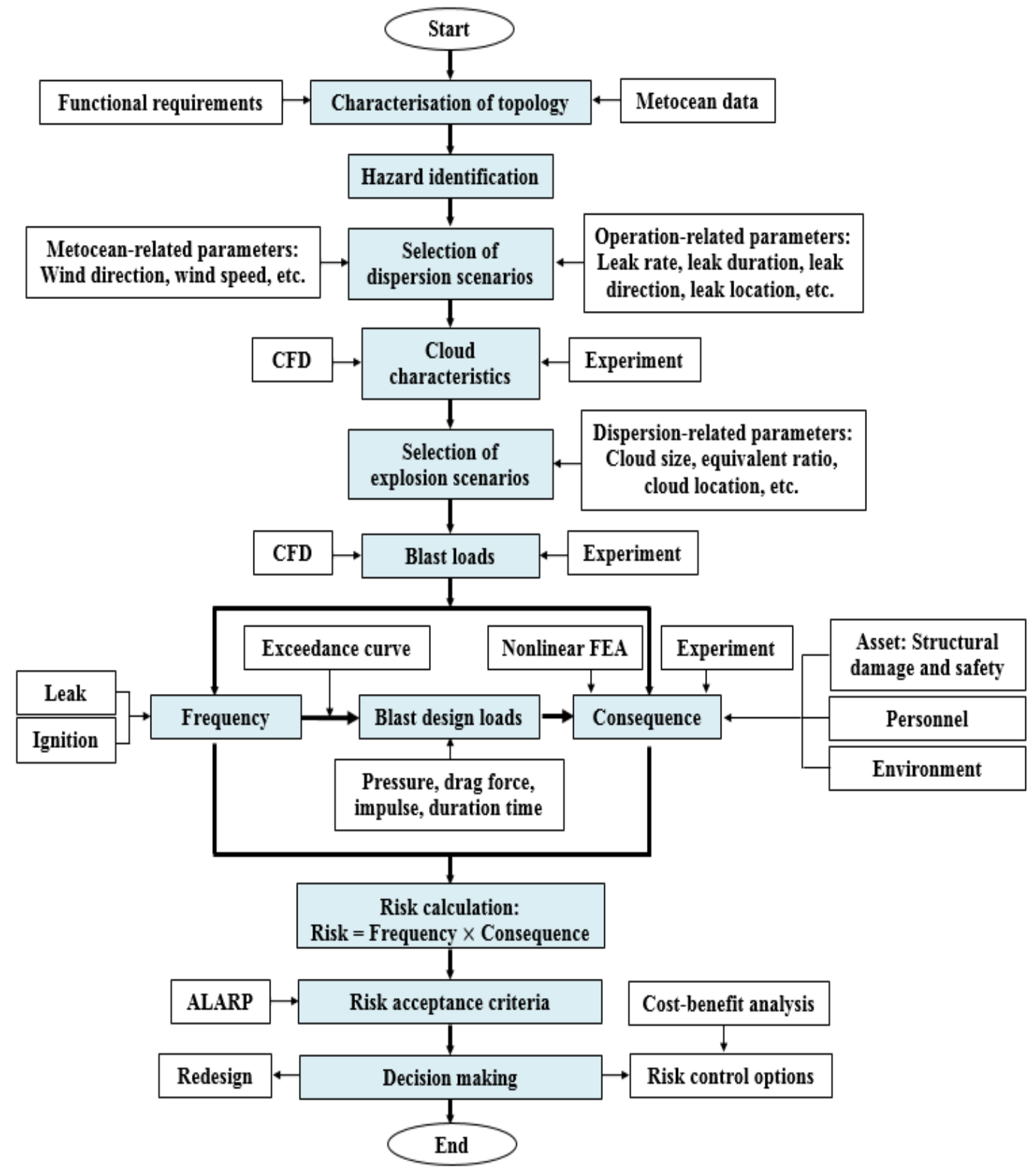

Figure 1 A procedure for the quantitative explosion risk assessment and management proposed by Paik et al. (2014) 


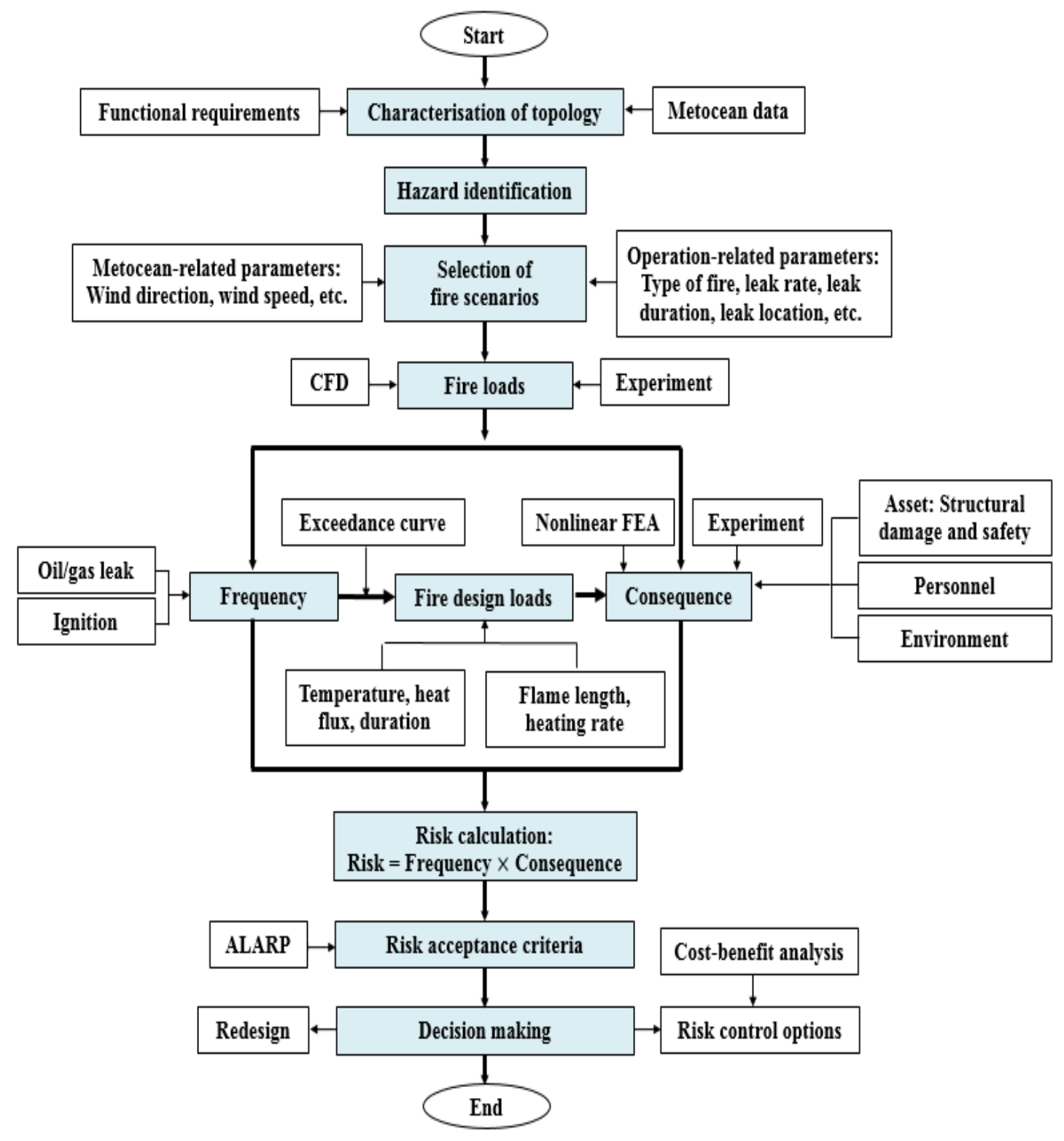

Figure 2 A procedure for the quantitative fire risk assessment and management proposed by Paik et al. (2013)

The present paper focuses on the overpressure loads arising from hydrocarbon explosions. There are a number of industry practices that define overpressure loads (Paik and Thayamballi 2007, ABS 2013, API 2006, ISO 2014, Spouge 1999, NORSOK 2010, LR 2014). Given the degree of uncertainty involved, such industry practices don't necessarily meet the needs at some practical problems (Paik et al. 2012). It is recognised that CFD computations are a powerful tool to identify the overpressure loads. However, their resulting accuracy is not always successful, and validation by comparison with an experimental database is therefore highly desirable. The objective of the present study was to experimentally and numerically investigate the effects of structural congestion and surrounding obstacles on the explosion overpressure loads. 
Many tests were reported in the literature. The MERGE experiments were coordinated by British Gas at the Spadeadam test site in the UK (Mercx et al. 1994). The experiments were performed with varying test module geometry. Two test cases of MERGE-E and $\mathrm{C}$ were conducted on a large scale with an $8 \times 8 \times 4 \mathrm{~m}$ obstruction array and a $360-\mathrm{m}^{3}$ flammable cloud. Four test cases of MERGE$\mathrm{A}, \mathrm{B}, \mathrm{C}$ and D were conducted at medium scale with a $4 \times 4 \times 2 \mathrm{~m}$ obstruction array and a $45-\mathrm{m}^{3}$ flammable cloud space.

A number of oil and gas companies participated in the BFETS Phase II experiments. The experiments were conducted to study explosion and fire at offshore installations. The projects were performed by British Gas at the Spadeadam test site (Selby 1998). Twenty-seven different large-scale explosion test models were conducted with $1,500 \mathrm{~m}^{3}$ in natural gas and air mixture and test model dimensions of $25.6 \times 8 \times 8 \mathrm{~m}$. The influential parameters studied in the experiment were the congestion (low, high), ignition point (centre and end) and water deluge system.

The HSE Phase 3A experiments involved large-scale models for explosion with methane-dominated natural gas (Al-Hassan 1998). These studies were performed by the UK Health and Safety Executive (HSE) in cooperation with Advantica. The objective of these tests was to examine scenarios with less confinement and higher levels of congestion and to evaluate end and central ignition cases. A number of the experiments were conducted using water mitigation. The dimensions of the test models were 28 $\times 12 \times 8 \mathrm{~m}$ with a solid roof but without walls.

The HSE Phase 3B test was carried out by a consortium comprising Advantica, GexCon and Shell Global Solutions. The test was performed at the GexCon and Advantica test sites. It was conducted to study ignited dispersion characteristics and to learn more about the explosion development in realistic gas clouds that is distinct from explosions of pre-mixed stoichiometric clouds. The models had a medium-scale geometry of $50 \mathrm{~m}^{3}$ and a large-scale geometry of $28 \times 12 \times 8 \mathrm{~m}$ or 2,600 $\mathrm{m}^{3}$, with a gas cloud formed from a gas release.

In addition to the previously noted tests, CFD computations are available in the literature (e.g., Hansen et al. 2010) and use the FLACS CFD code developed by the GexCon company in Norway. Through such studies, it has been observed that the CFD computations are in a good agreement with the test database in the near-field area of the ignition point, but underestimated in the far-field area.

In recent years, combined experimental and numerical studies of hydrocarbon explosions have been provided. Bauwens et al. (2010) performed a series of explosion tests and CFD computations with varying ignition locations and vent sizes and obstacles in a $64-\mathrm{m}^{3}$ chamber without a pressure relief panel. Pedersen and Middha (2012) performed an experiment and CFD computations with vented gas explosions.

Regardless of the previous contributions to the experimental and numerical studies associated with hydrocarbon explosions, there remain many technical issues to resolve. Most of all, details about the test database are limited to access, and it may be difficult to use such a test database for validation and other purposes. In the present study, an experimental study of the test module $20 \times 13.5 \times 9 \mathrm{~m}$ in size was performed. The FLACS CFD computations were also performed with varying degrees of structural congestion. The effect of surrounding structures was also studied.

\section{Test Setup}

\subsection{Test module}

The experiment was undertaken using the module at the test site of the Korea Ship and Offshore 
Research Institute (KOSORI) on the Hadong Campus of Pusan National University in Korea. The test module was developed at one-half scale for the topside structure of a very large crude oil carrier (VLCC) class FLNG, which consisted of a process deck, mezzanine deck and upper deck together with vessels and pipe racks. Figure 3 presents the test module together with the principal dimensions. Figure 4 details the layout of the test module at the individual decks.

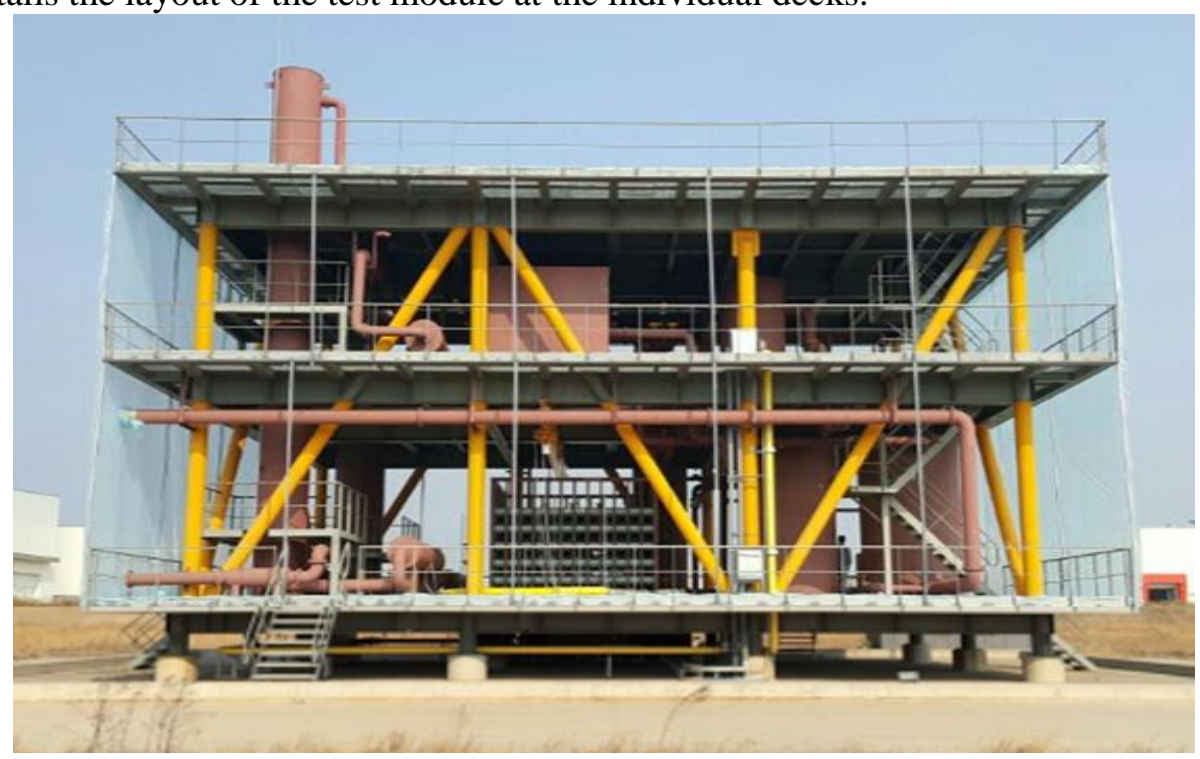

(a) Side view of the test module

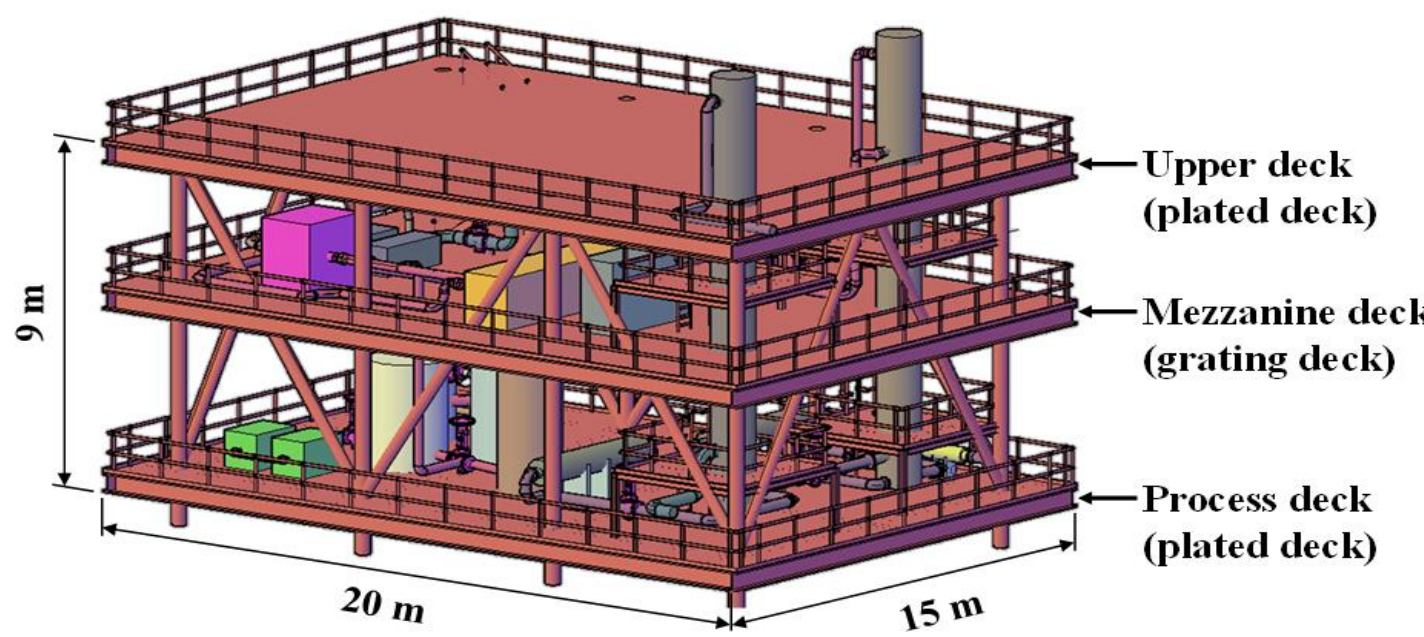

(b) Principal dimensions of the test module

Figure 3 A 1/2 scale explosion test module on the Hadong Campus of the Korea Ship and Offshore Research Institute (KOSORI) at Pusan National University 


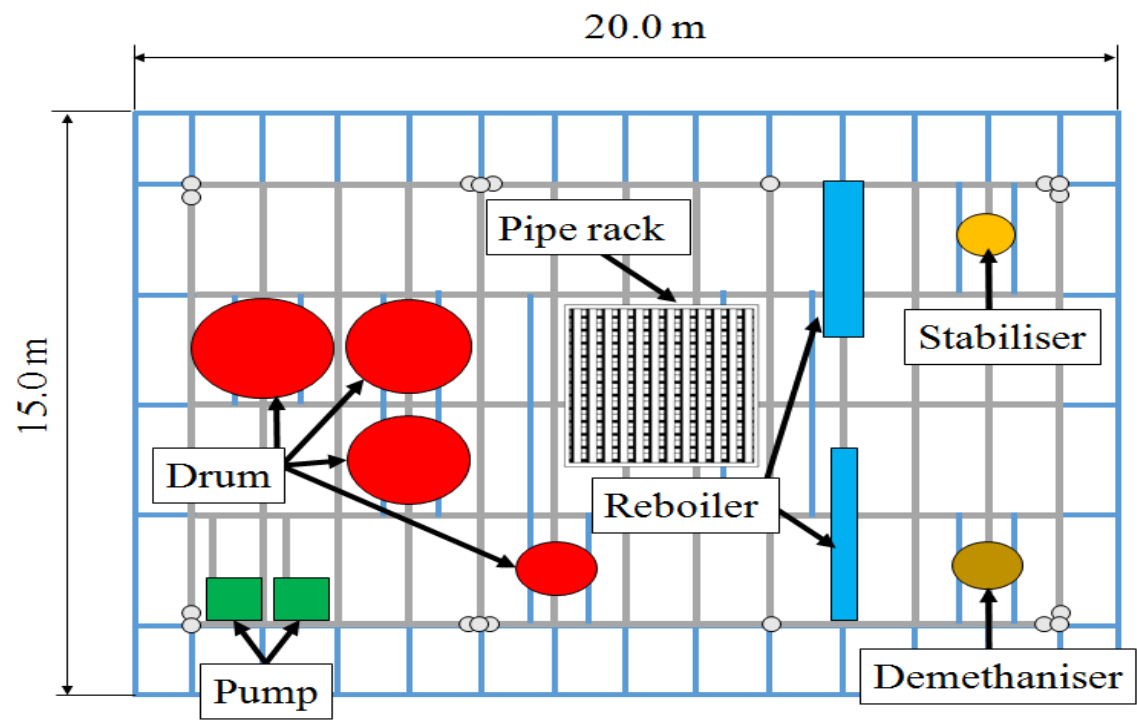

(a) At process deck

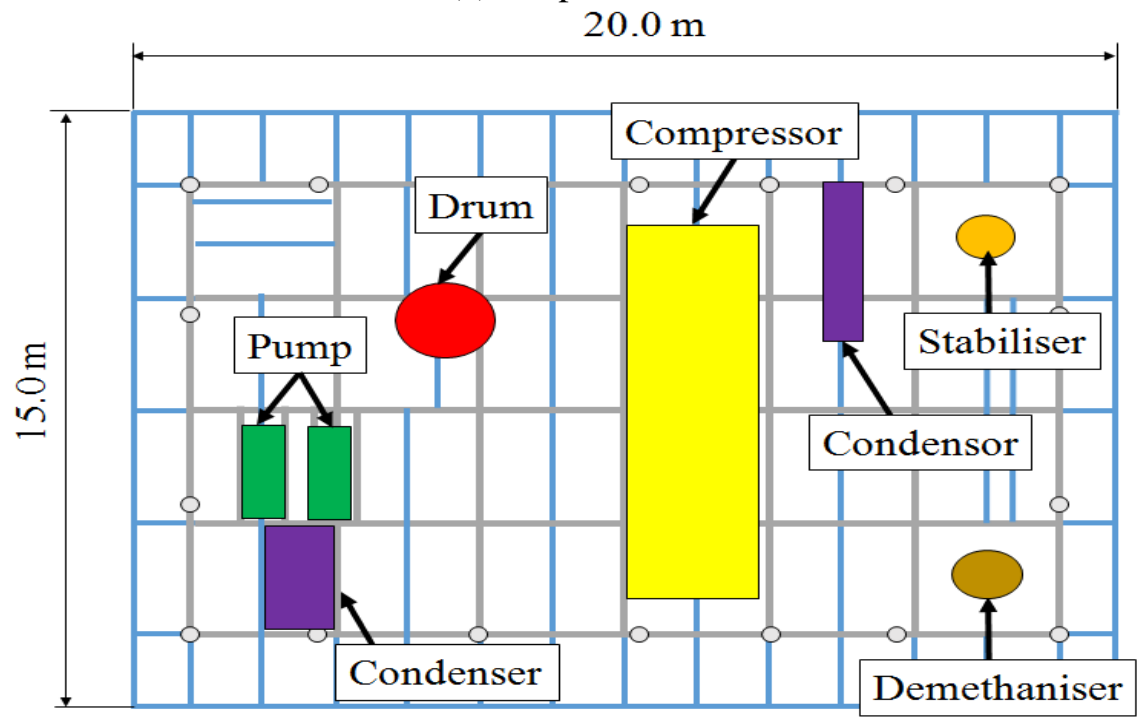

(b) At mezzanine deck

Figure 4 Layout of the test module

A pipe rack structure covered by a very thin plastic or vinyl sheet $52 \mathrm{~m}^{3}$ in size was installed in the centre of the process deck. Tubular structural members were arranged in a grid form in association with the degree of structural congestion. Figure 5 presents the pipe rack structure covered by a very thin plastic sheet. Figure 6 details the layout of the pipe rack structure. The propane gas with an explosive limit of 2.1-9.5\% was filled in to meet the stoichiometric condition. Table 1 indicates the chemical composition of the gas used in the test. The ignition was controlled by an electrical source located at the centre of the pipe rack as shown in Figure 7. 


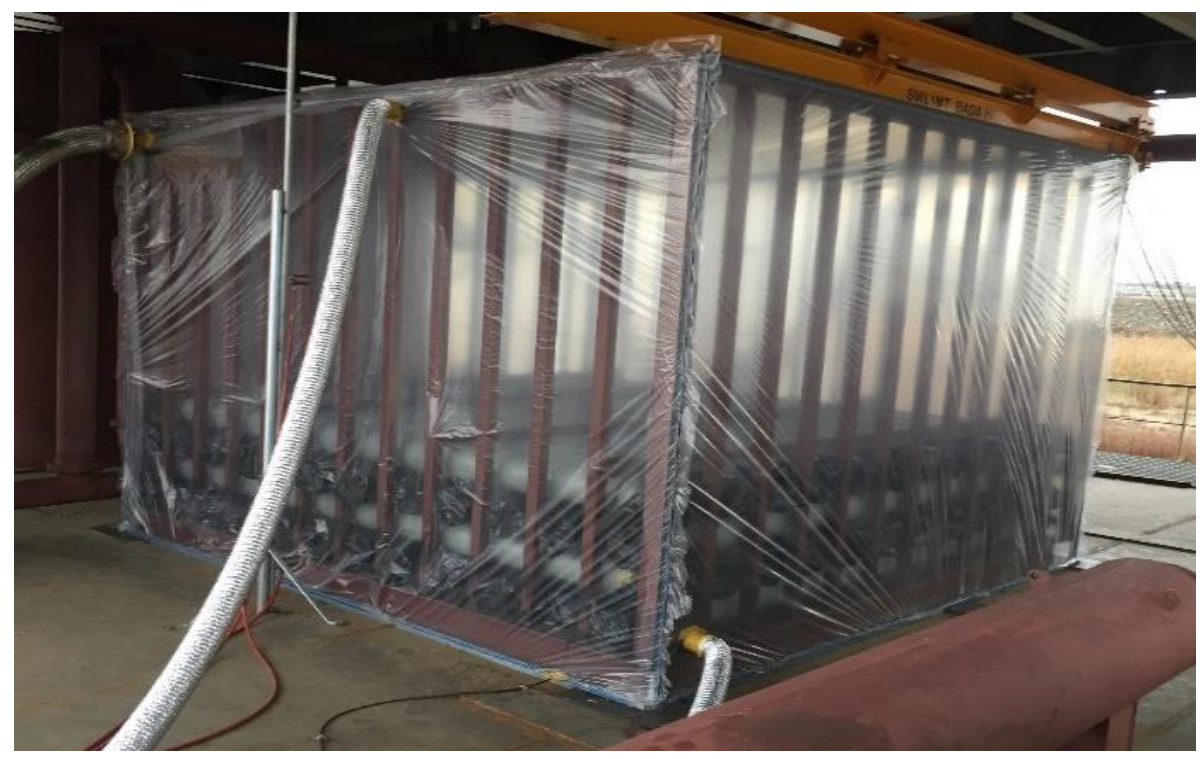

Figure 5 Pipe rack structure covered by a very thin plastic sheet

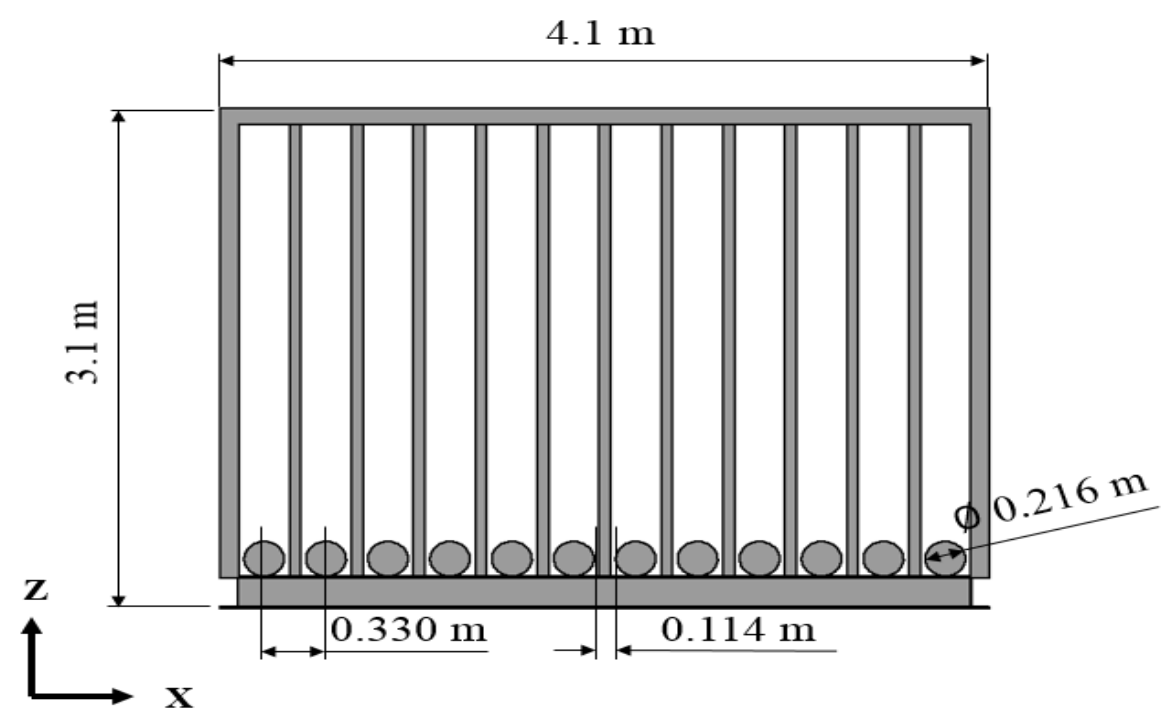



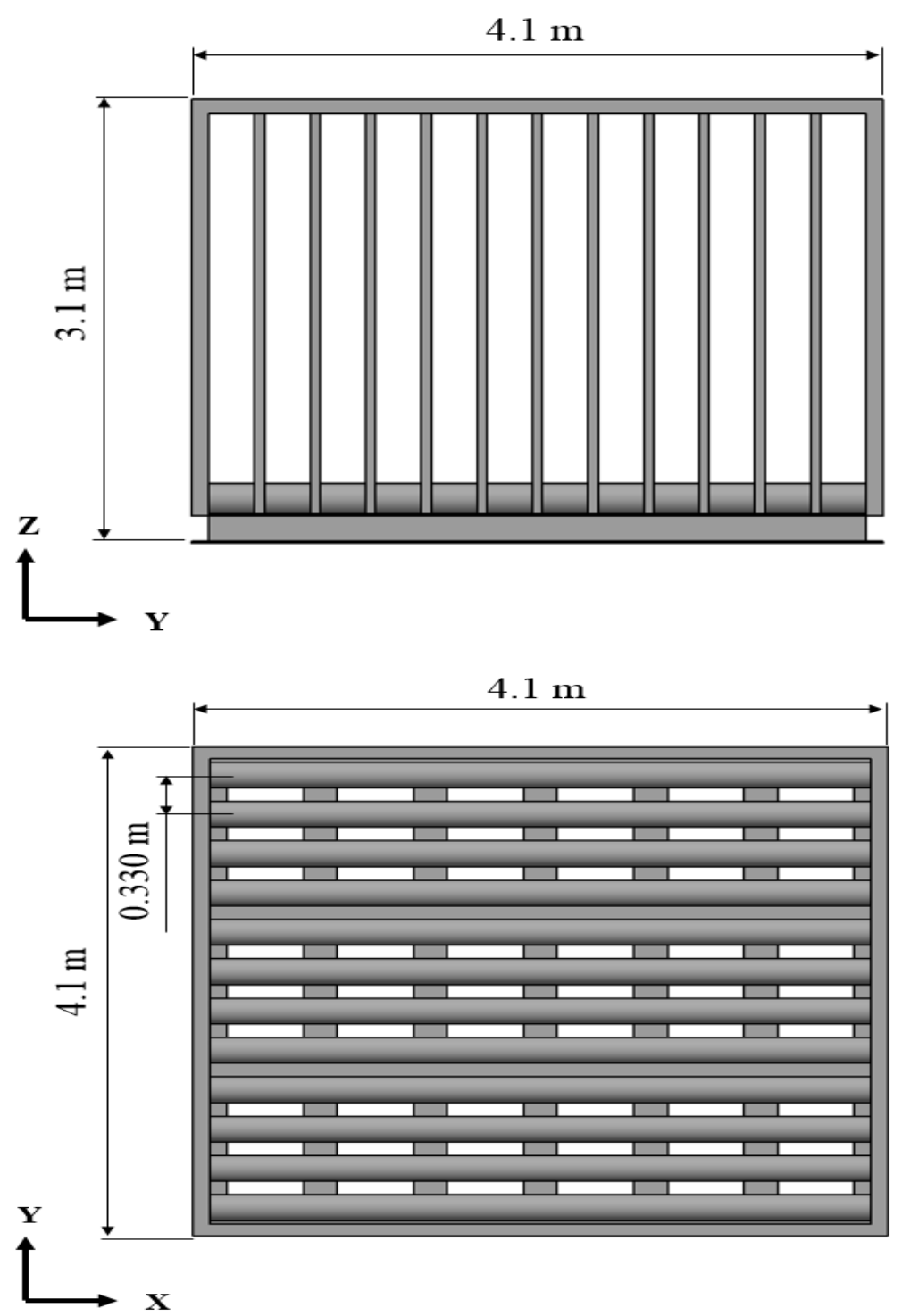

Figure 6 (a) Layout of the pipe rack structure with 12 pipes 

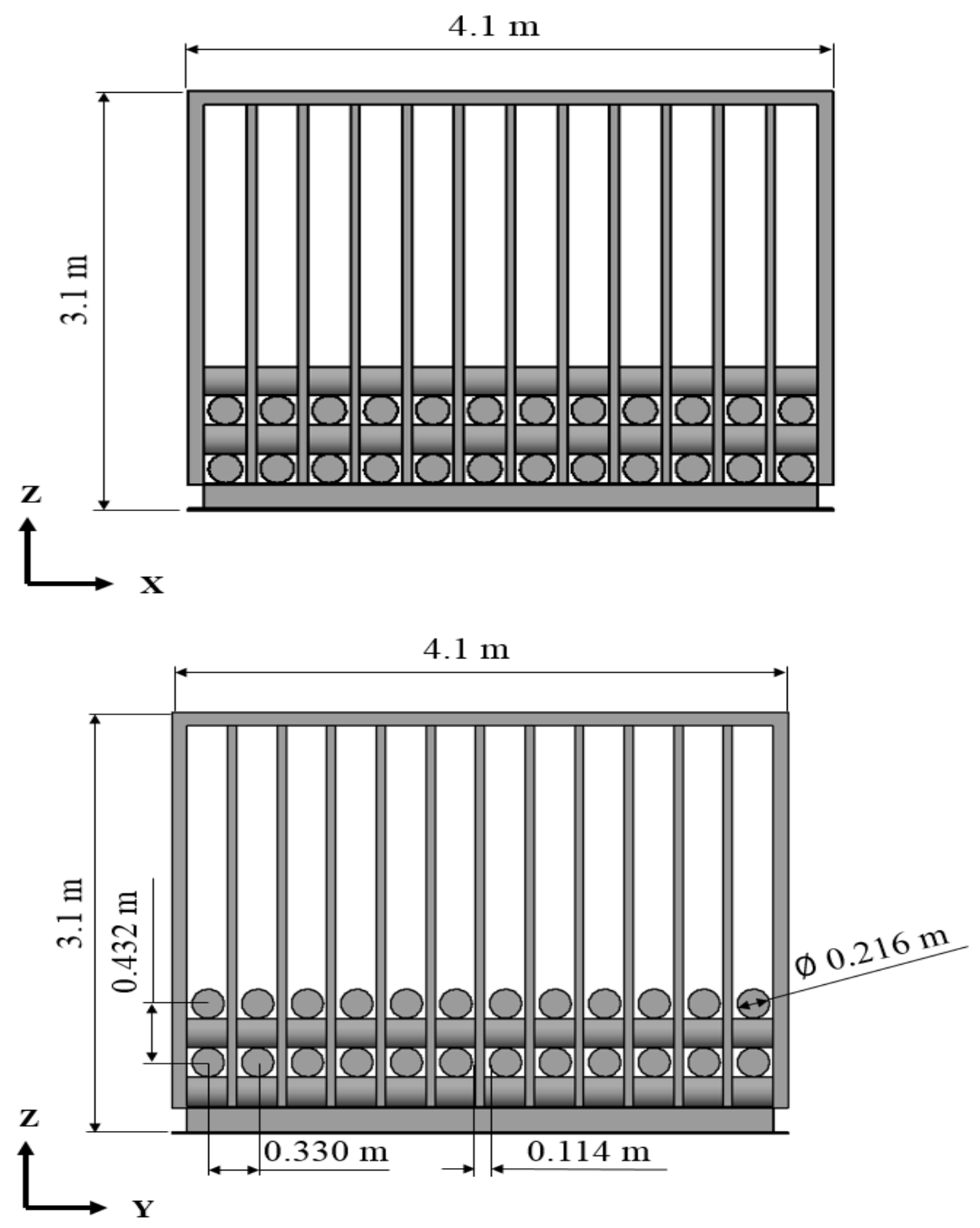


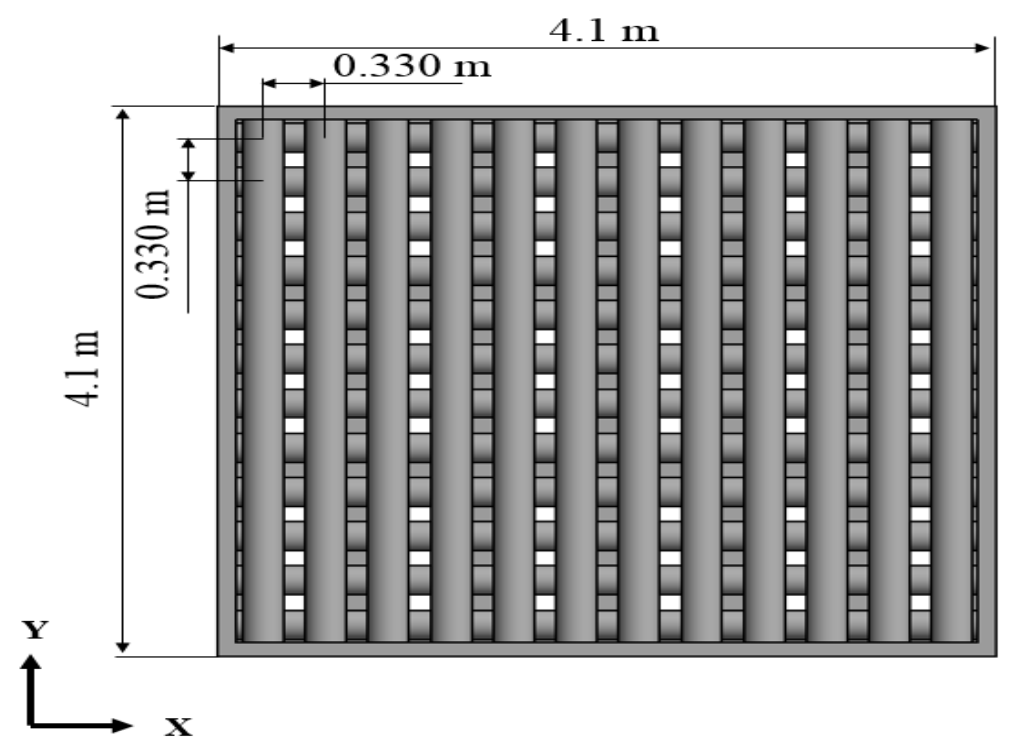

Figure 6 (b) Layout of the pipe rack structure with 48 pipes
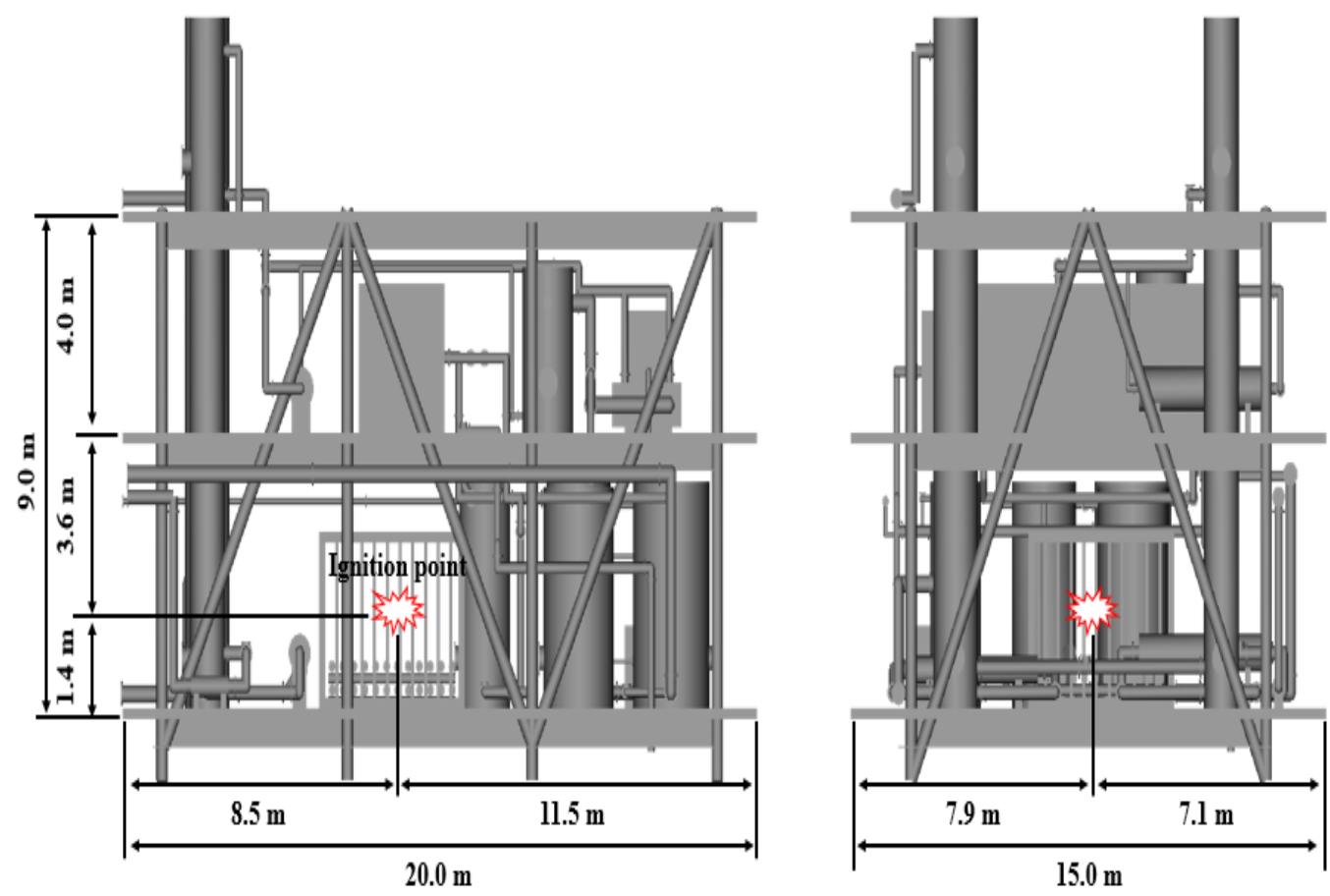

Figure 7 Location of the ignition point 
Table 1. Chemical composition of the propane gas used in the test

\begin{tabular}{rccccc}
\hline Total & Propane & Ethane & Butane & Total olefins & Methane \\
\hline $100 \%$ & $98.19 \%$ & $0.98 \%$ & $0.79 \%$ & $0.03 \%$ & $0.01 \%$ \\
\hline
\end{tabular}

\subsection{Test scenarios}

Five scenarios were considered in which the number of pipes varied from 0 to 12, 24, 36 and 48 pipes, respectively. Table 2 indicates the details of the test scenarios.

Table 2. Scenarios of gas explosion experiments

\begin{tabular}{llll}
\hline Case No. & $\begin{array}{l}\text { Number } \\
\text { of pipes }\end{array}$ & Type of gas & $\begin{array}{l}\text { Location } \\
\text { of ignition }\end{array}$ \\
\hline I & 0 & & \\
II & 12 & Propane & Centre of gas cloud \\
III & 24 & & \\
IV & 36 & & \\
V & 48 & & \\
\hline
\end{tabular}

\subsection{Data acquisition}

The overpressure loads and related pressure characteristics with time were measured using pressure sensors attached to the points or locations of interest in the test module. Table 3 presents the specification of the pressure sensors. Figure 8 shows an example of the attached pressure sensors. The locations of the pressure sensors were determined based on FLACS CFD simulations conducted before the main experiment. Twenty-four pressure sensors were installed where the explosion loads were sensitively affected. Figure 9 and Table 4 present the details of the pressure sensor locations.

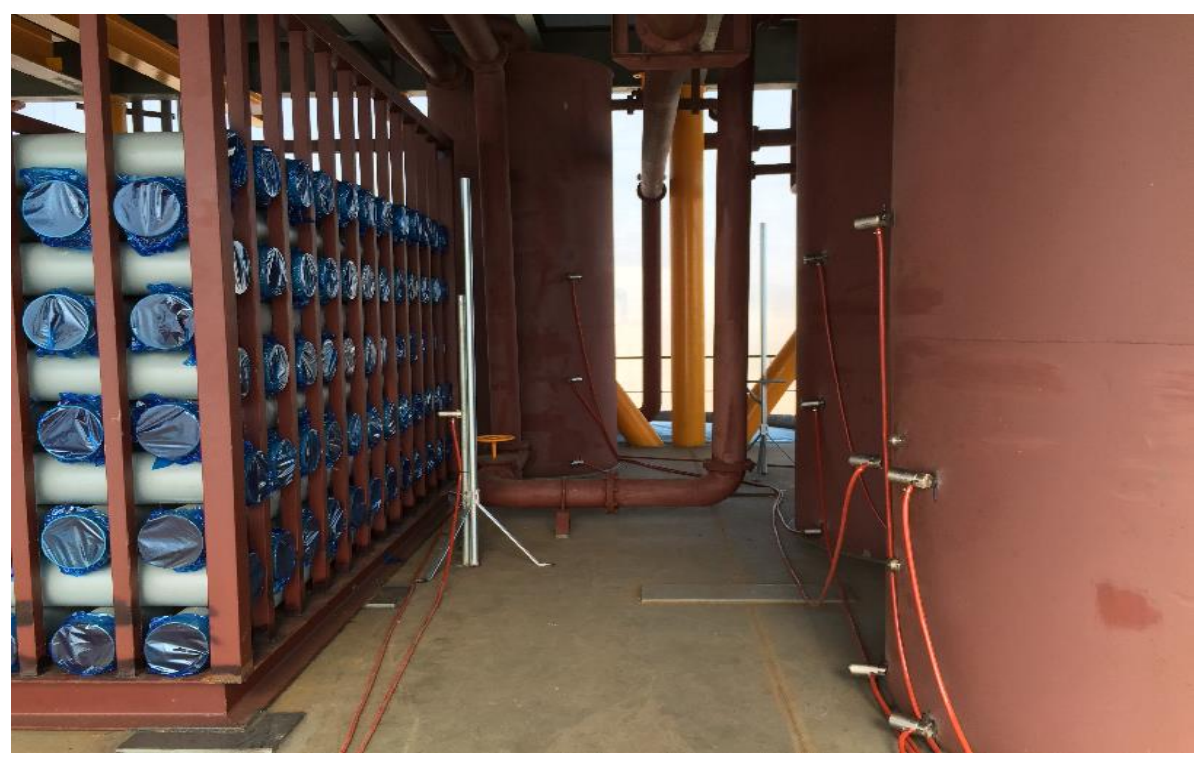

Figure 8 Installation of pressure sensors 
Table 3 Specification of the pressure sensor

\begin{tabular}{ll}
\hline Range & $0-50^{\circ} \mathrm{C}$ \\
\hline Proof pressure & Bar abs and $\leq 3.4$ \\
\hline Excitation & 9 to $30 \mathrm{Vdc}$ (reverse polarity and overvoltage protected) \\
\hline Output & $\begin{array}{l}4 \text { to } 20 \mathrm{~mA} \text { accuracy: } \pm 0.25 \% \text { (includes linearity, hysteresis and } \\
\text { repeatability) }\end{array}$ \\
\hline Blast pressure & $500 \%$ capacity or 1.7 bar, whichever was greater \\
\hline Response time & $<1 \mathrm{~ms}$ \\
\hline Shock & $50 \mathrm{~g}, 11 \mathrm{~ms}$ half-sine shock \\
\hline Vibration & $\pm 20 \mathrm{~g}$ \\
\hline
\end{tabular}

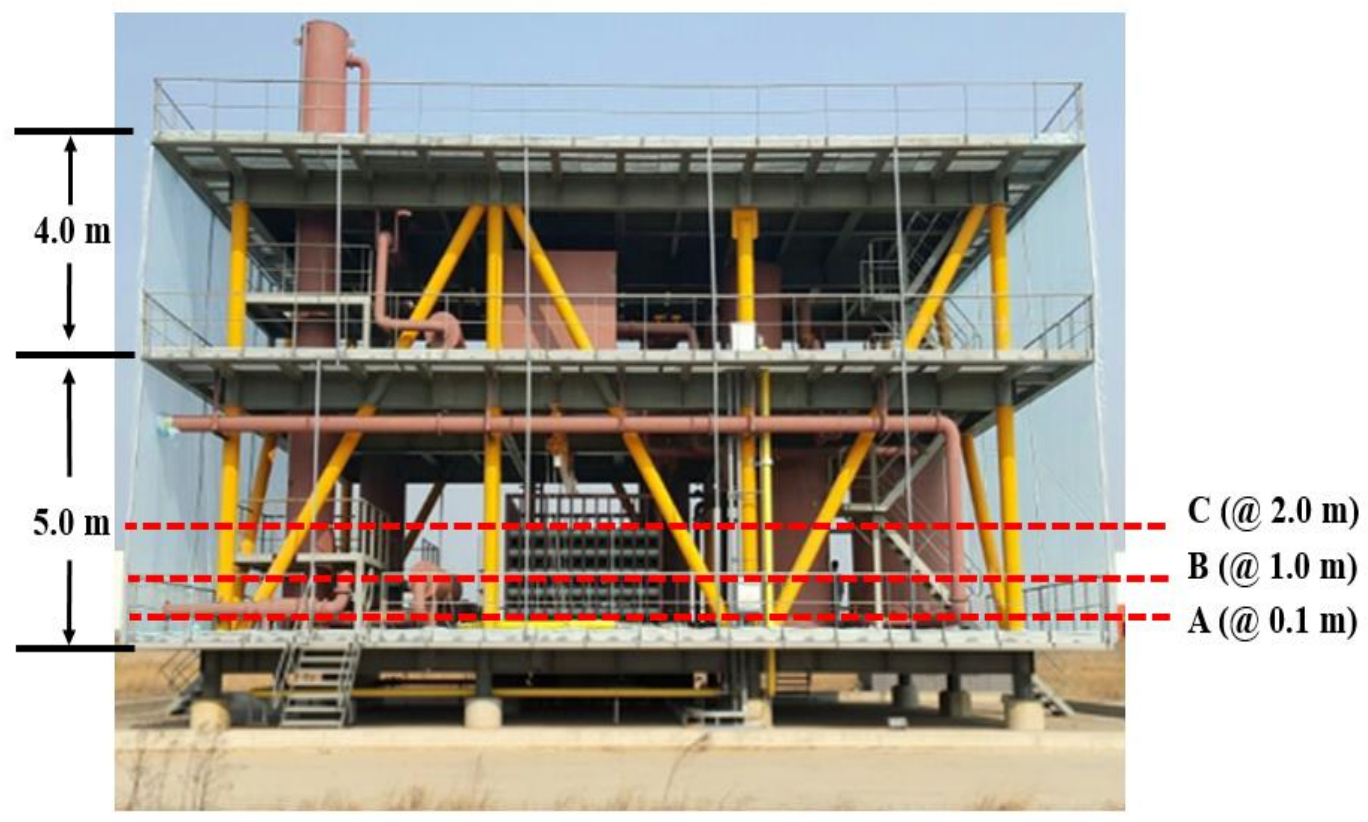

(a) Elevation view of pressure sensors 


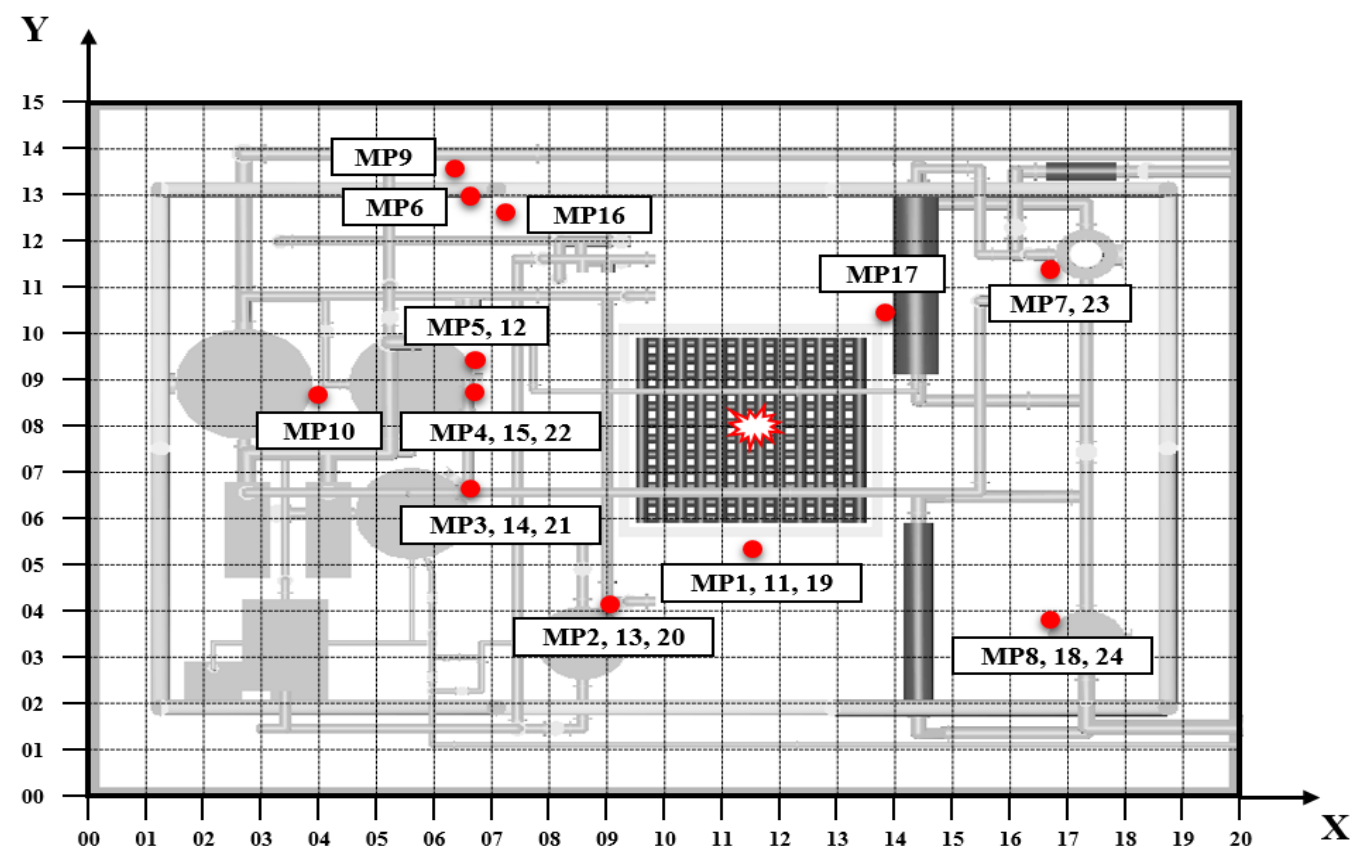

(b) Locations of pressure sensors

Figure 9 Locations of the pressure sensors

Table 4 Locations of the pressure sensors in coordinates (unit: $\mathrm{m}$ )

\begin{tabular}{llll|llll}
\hline No. & $\mathrm{X}$ & $\mathrm{Y}$ & $\mathrm{Z}$ & No. & $\mathrm{X}$ & $\mathrm{Y}$ & $\mathrm{Z}$ \\
\hline MP1 & 11.50 & 5.28 & 0.1 & MP13 & 9.00 & 4.00 & 1.0 \\
\hline MP2 & 9.00 & 4.00 & 0.1 & MP14 & 6.50 & 6.50 & 1.0 \\
\hline MP3 & 6.50 & 6.50 & 0.1 & MP15 & 6.75 & 8.75 & 1.0 \\
\hline MP4 & 6.75 & 8.75 & 0.1 & MP16 & 7.25 & 12.75 & 1.0 \\
\hline MP5 & 6.75 & 9.25 & 0.1 & MP17 & 14.00 & 10.50 & 1.0 \\
\hline MP6 & 6.75 & 13.00 & 0.1 & MP18 & 16.75 & 3.75 & 1.0 \\
\hline MP7 & 16.75 & 11.25 & 0.1 & MP19 & 11.50 & 5.28 & 2.0 \\
\hline MP8 & 16.75 & 3.75 & 0.1 & MP20 & 9.00 & 4.00 & 2.0 \\
\hline MP9 & 6.50 & 13.25 & 0.1 & MP21 & 6.50 & 6.50 & 2.0 \\
\hline MP10 & 4.00 & 8.75 & 0.1 & MP22 & 6.75 & 8.75 & 2.0 \\
\hline MP11 & 11.50 & 5.28 & 1.0 & MP23 & 16.75 & 11.25 & 2.0 \\
\hline MP12 & 6.75 & 9.25 & 1.0 & MP24 & 16.75 & 3.75 & 2.0 \\
\hline & & & & & & & \\
\hline
\end{tabular}

\section{Test Results}

\subsection{Summary and discussion}

Figure 10 presents the overpressure loads-time history at monitoring point 1 (MP1). The pressure contained a large amount of rapid oscillations due to a combination of real pressure fluctuations in the pressure sensor and noise in the electronic equipment. The structure did not respond to such fluctuations because the natural frequencies were lower than the frequencies of such oscillations (Czujko 2001). A moving average (MA) value of the filtering techniques available was used. A mean value of the overpressure loads was then calculated within a time interval of $1 \mathrm{~ms}$ to reduce the 
influence of short spikes. Figure 10 plots the 1-ms moving average of the overpressure loads with time.

Figure 10 shows that the overpressure loads rose to a peak value within a very short period of rise time and decayed sharply. The rise time until the peak overpressure loads were reached differed depending on the structural congestion. The rise time became shorter with increase in the degree of structural congestion. The overpressure loads fell into negative values compared with the ambient pressure and were recovered to the ambient pressure as the impact energy was released.

Table 5 presents the peak values of the overpressure loads with different numbers of pipes and sensor locations. The peak values occurred at the same location for all of the test cases except in the case of 48 pipes, which was the most congested scenario. This observation indicates that the peak value of overpressure loads might have occurred in the same location when the degree of structural congestion was below a critical value.

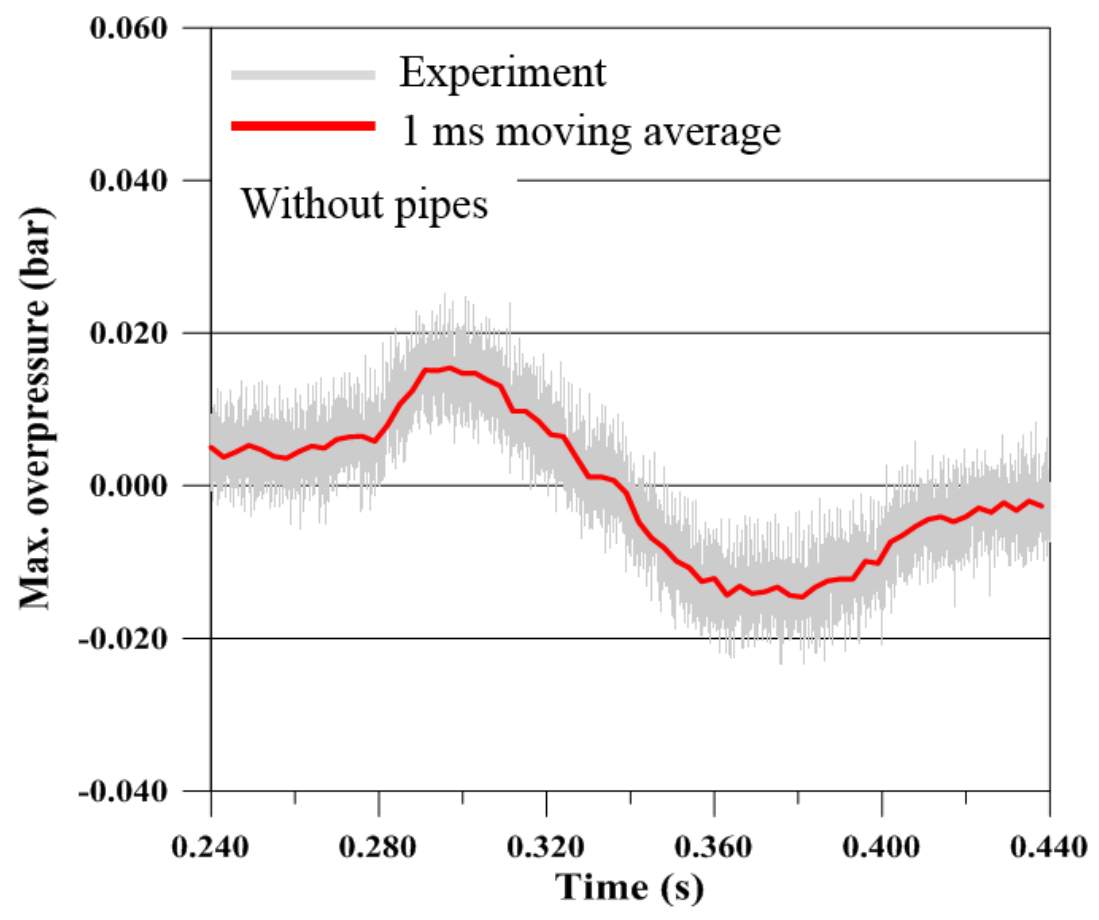

(a) Without pipes 


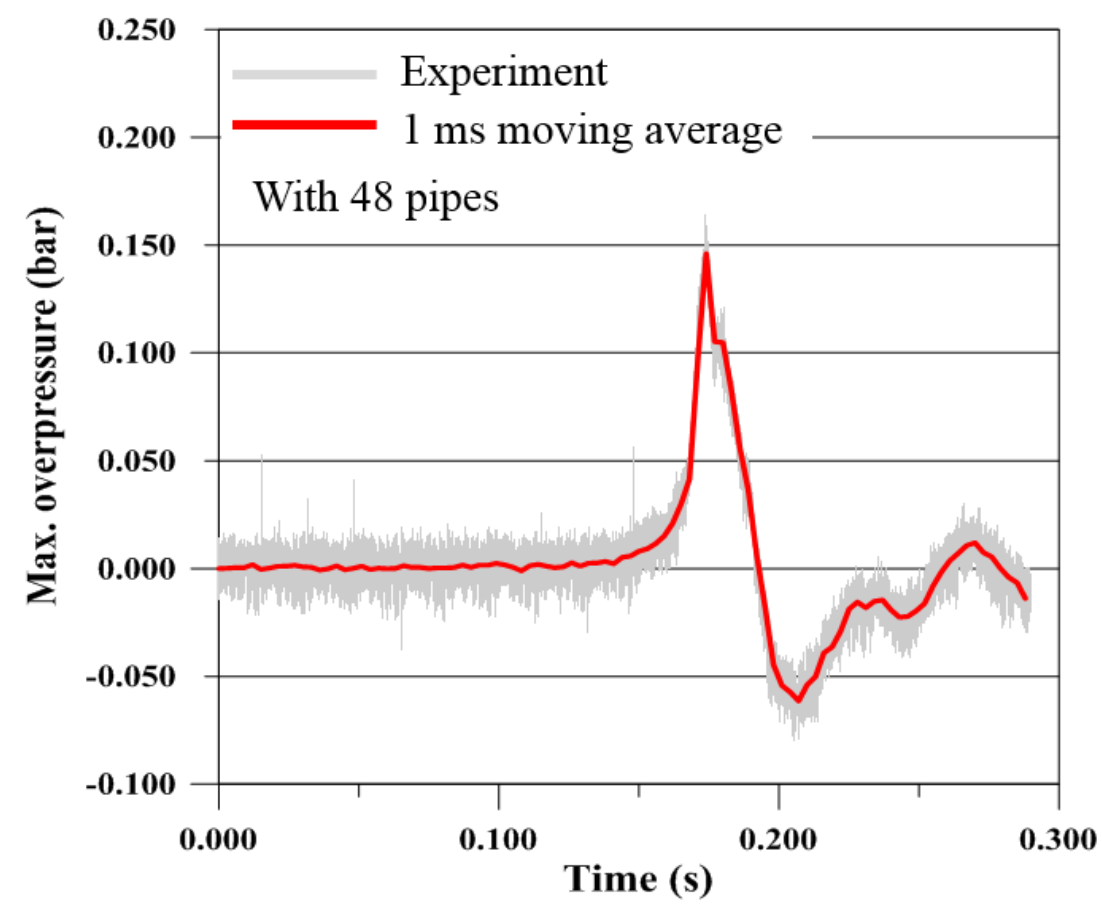

(b) With 48 pipes

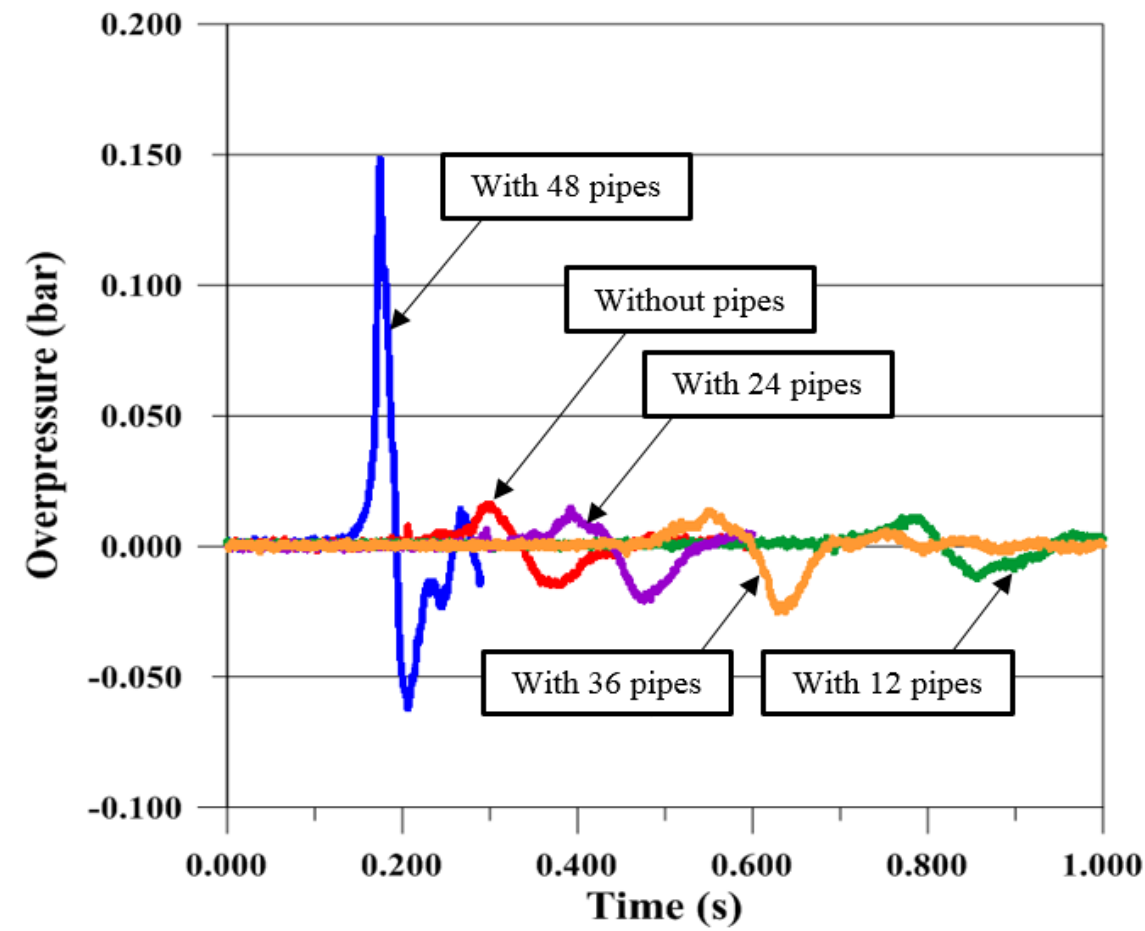

(c) All cases

Figure 10 Overpressure loads-time history at the pressure sensor location MP1 with or without pipes 
Table 5 Peak overpressure at monitoring points (unit: bar)

\begin{tabular}{|c|c|c|c|c|c|}
\hline \multirow{2}{*}{$\begin{array}{c}\text { Sensor } \\
\text { location }\end{array}$} & \multicolumn{5}{|c|}{ Number of pipes } \\
\hline & 0 & 12 & 24 & 36 & 48 \\
\hline MP1 & 0.0165 & 0.0112 & 0.0151 & 0.0139 & 0.1482 \\
\hline MP2 & 0.0151 & 0.0129 & 0.0161 & 0.0142 & 0.2233 \\
\hline MP3 & 0.0169 & 0.0152 & 0.0188 & 0.0172 & 0.1961 \\
\hline MP4 & 0.0157 & 0.0160 & 0.0164 & 0.0178 & 0.1752 \\
\hline MP5 & 0.0179 & 0.0175 & 0.0194 & 0.0203 & 0.1679 \\
\hline MP6 & 0.0087 & 0.0088 & 0.0086 & 0.0095 & 0.0626 \\
\hline MP7 & 0.0116 & 0.0090 & 0.0092 & 0.0103 & 0.0798 \\
\hline MP8 & 0.0089 & 0.0060 & 0.0055 & 0.0068 & 0.0819 \\
\hline MP9 & 0.0101 & 0.0078 & 0.0106 & 0.0097 & 0.0633 \\
\hline MP10 & 0.0049 & 0.0038 & 0.0046 & 0.0053 & 0.0801 \\
\hline MP11 & 0.0184 & 0.0192 & 0.0159 & 0.0191 & 0.1124 \\
\hline MP12 & 0.0160 & 0.0102 & 0.0138 & 0.0161 & 0.1666 \\
\hline MP13 & 0.0175 & 0.0149 & 0.0147 & 0.0160 & 0.1990 \\
\hline MP14 & 0.0154 & 0.0117 & 0.0155 & 0.0145 & 0.1920 \\
\hline MP15 & 0.0181 & 0.0165 & 0.0177 & 0.0190 & 0.1645 \\
\hline MP16 & 0.0021 & 0.0021 & 0.0021 & 0.0025 & 0.0356 \\
\hline MP17 & 0.0081 & 0.0049 & 0.0077 & 0.0033 & 0.0744 \\
\hline MP18 & 0.0137 & 0.0122 & 0.0132 & 0.0146 & 0.0910 \\
\hline MP19 & 0.0201 & 0.0152 & 0.0160 & 0.0174 & 0.1588 \\
\hline MP20 & 0.0130 & 0.0229 & 0.0125 & 0.0128 & 0.0992 \\
\hline MP21 & 0.0143 & 0.0120 & 0.0129 & 0.0148 & 0.1607 \\
\hline MP22 & 0.0255 & 0.0215 & 0.0245 & 0.0236 & 0.1458 \\
\hline MP23 & 0.0122 & 0.0114 & 0.0107 & 0.0109 & 0.0714 \\
\hline MP24 & 0.0128 & 0.0109 & 0.0106 & 0.0124 & 0.0823 \\
\hline
\end{tabular}

\subsection{Effect of structural congestion}

The degree of structural congestion is often defined using a porosity factor given by

Porosity $=1-\frac{\text { Volume of total structure }}{\text { Volume of total space }}$

According to this definition, the porosity becomes smaller as the degree of structural congestion increases. When no structural members exist, the porosity becomes 1.0. In this study, the porosities of the test models were determined as 1.0, 0.97, 0.93, 0.90, and 0.87 for scenarios $\mathrm{I}-\mathrm{V}$, respectively. 
Figure 11 presents the overpressure loads-time histories at different pressure sensor locations without pipes and with 48 pipes. Figure 12 and Table 6 compare the peak overpressure loads between different porosities. It is obvious that the structural congestion increased the overpressure loads significantly. The overpressure loads at lower elevations such as MP1, MP2 and MP3 with $0.1 \mathrm{~m}$ were greater than those at higher elevations such as MP11, MP13 and MP14 with $1.0 \mathrm{~m}$. The difference in the overpressure loads in the case of no pipes was small regardless of elevation.

Furthermore, the overpressure-time history was similar for all of the scenarios except scenario V. This implied that there must be a critical value of the structural congestion or porosity distinct from the sensitivity on the overpressure loads as shown in Figure 11, where the overpressure loads are almost unchanged at porosity above 0.88 but increase rapidly at porosity below 0.88 .

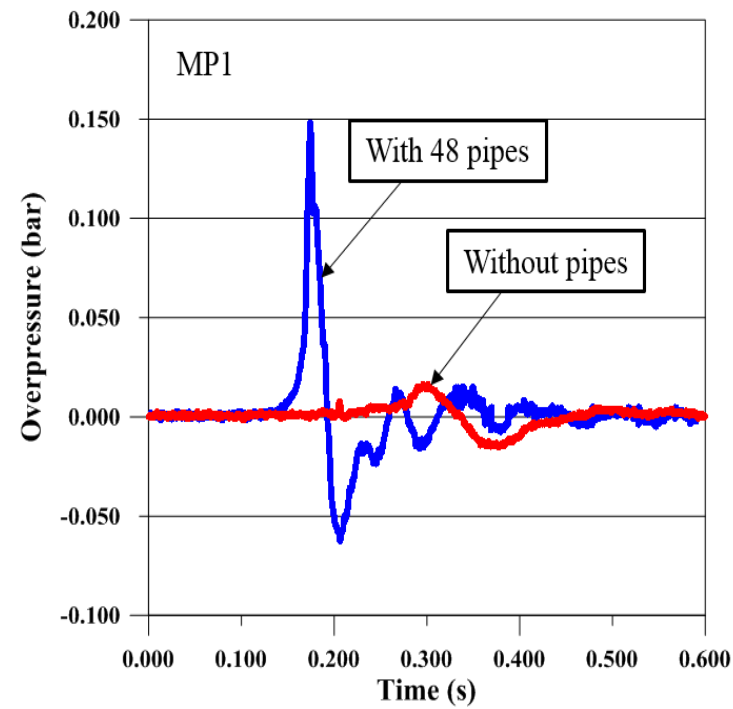

(a) Pressure sensor location MP1

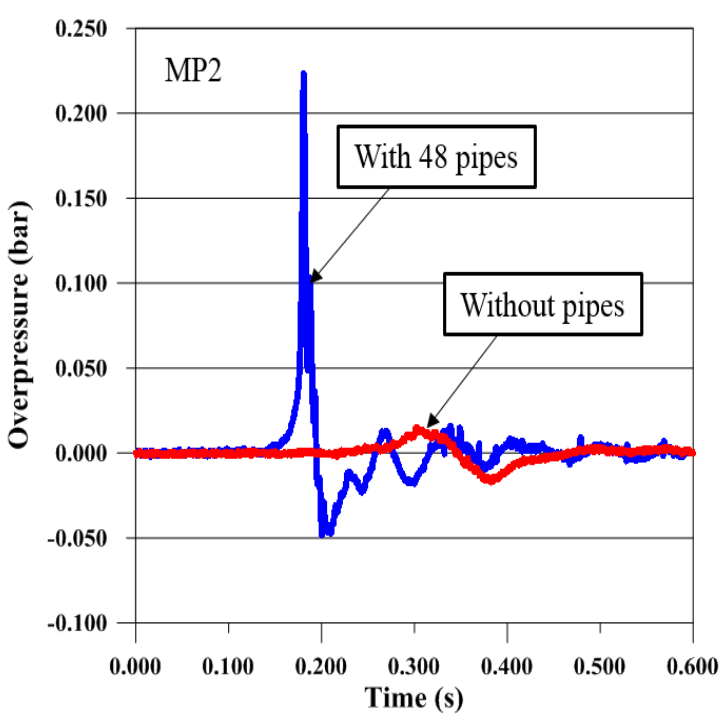

(c) Pressure sensor location MP2

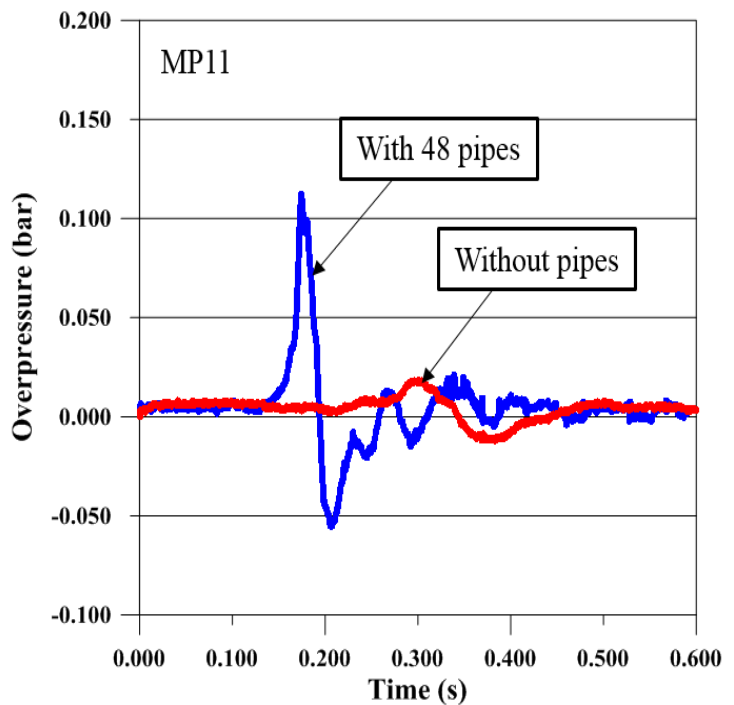

(b) Pressure sensor location MP11

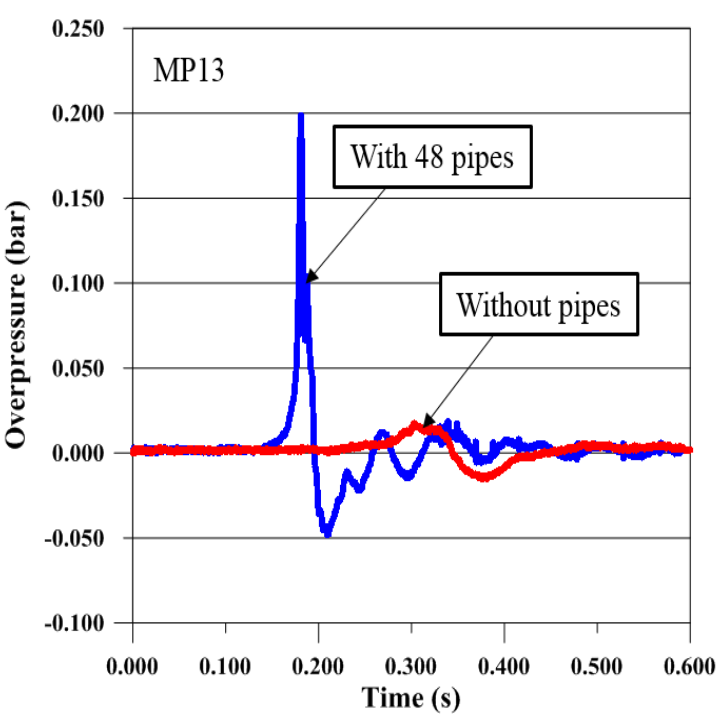

(d) Pressure sensor location MP13 


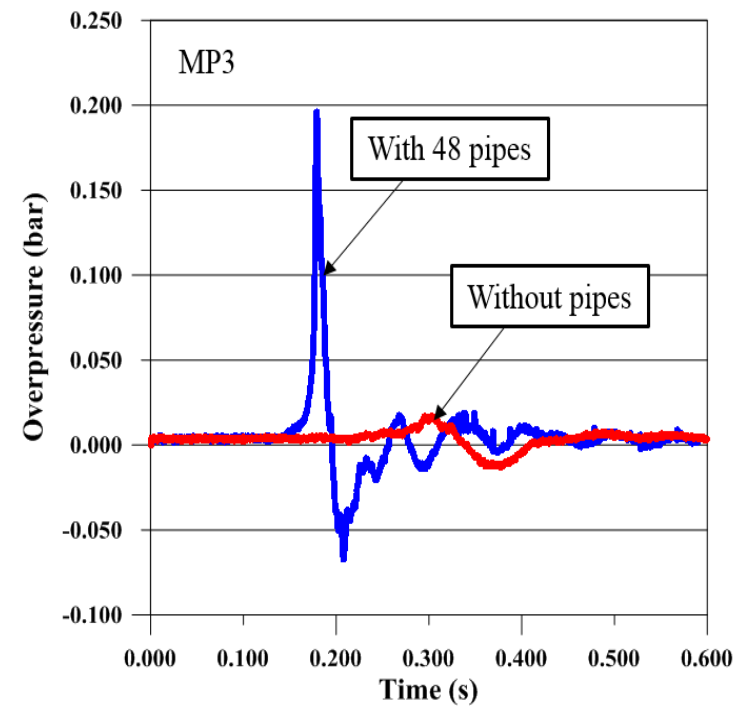

(e) Pressure sensor location MP3

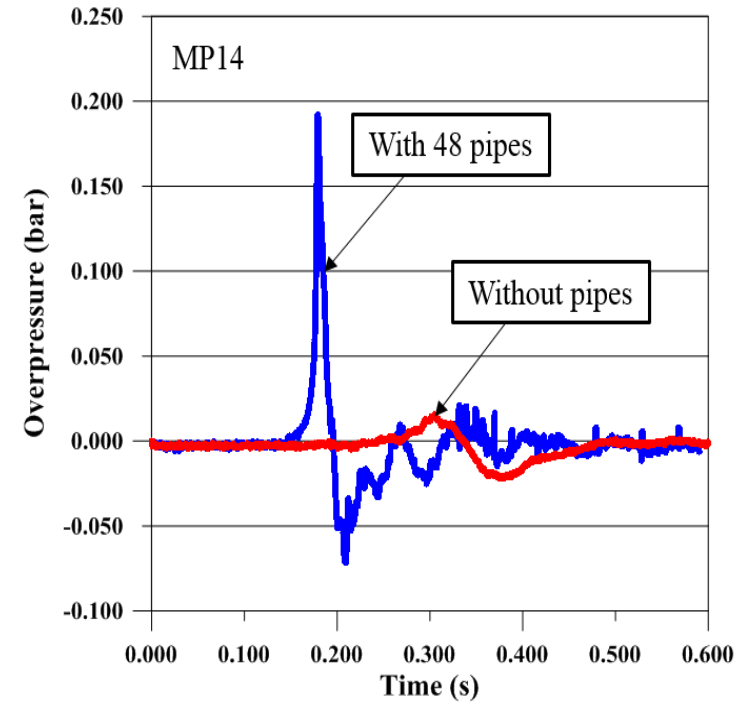

(f) Pressure sensor location MP14

Figure 11 Overpressure loads-time history at different pressure sensor locations without pipes and with 48 pipes

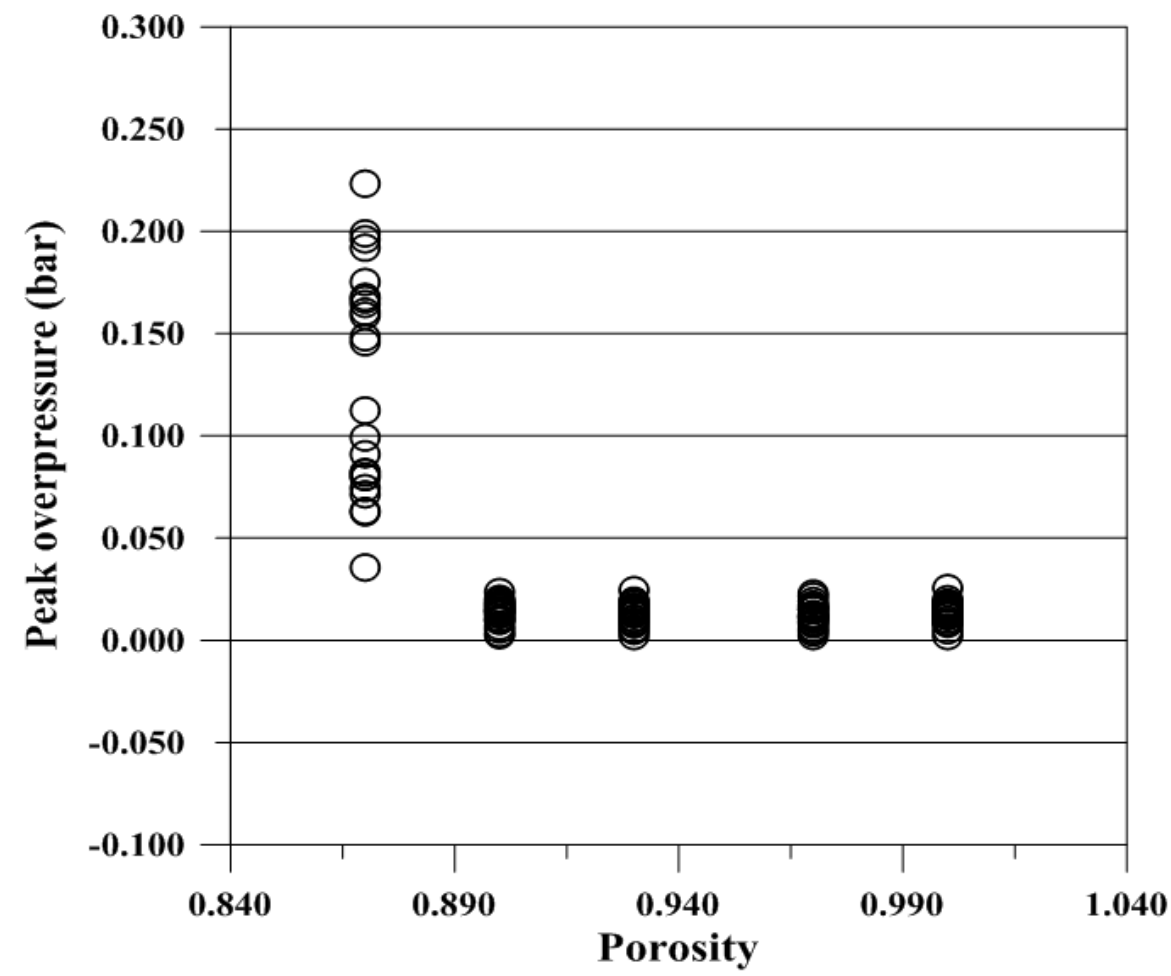

Figure 12 The relation between peak overpressure loads versus porosity

Table 6 Comparison of porosity and peak overpressure load with case of 12 pipes (Case II) at pressure sensor location MP4

\begin{tabular}{ccccc}
\hline \multirow{2}{*}{ Variables } & \multicolumn{5}{c}{ Rate } \\
\cline { 2 - 5 } & Case II / II & Case III / II & Case IV / II & Case V / II \\
\hline \multirow{2}{*}{ Porosity } & $100 \%$ & $96 \%$ & $93 \%$ & $90 \%$ \\
\hline
\end{tabular}




\begin{tabular}{ccccc}
\hline $\begin{array}{c}\text { Peak } \\
\text { overpressure }\end{array}$ & $100 \%$ & $103 \%$ & $111 \%$ & $1,095 \%$ \\
\hline
\end{tabular}

\section{Numerical study}

\subsection{FLACS CFD model}

FLACS code, version 10.4 (FLACS 2015) was adopted for the CFD computations. Figure 13 shows the FLACS CFD model for the test module in which the pipe rack structure had a volume of $52 \mathrm{~m}^{3}$ with dimensions of $4.1 \times 4.1 \times 3.1 \mathrm{~m}$. The CFD model, however, extended to the space which is as big as possible with $30 \times 30 \times 15 \mathrm{~m}$ so as to minimize the boundary effects.

The so-called Euler boundary condition is sometimes allocated for explosion CFD simulations. However, the present CFD model associated with the Euler boundary condition reflected negative overpressures as a pressure wave hits the boundary and a long distance was available to the boundaries in all directions. As such, the Euler boundary condition was not applied in the present CFD computations.

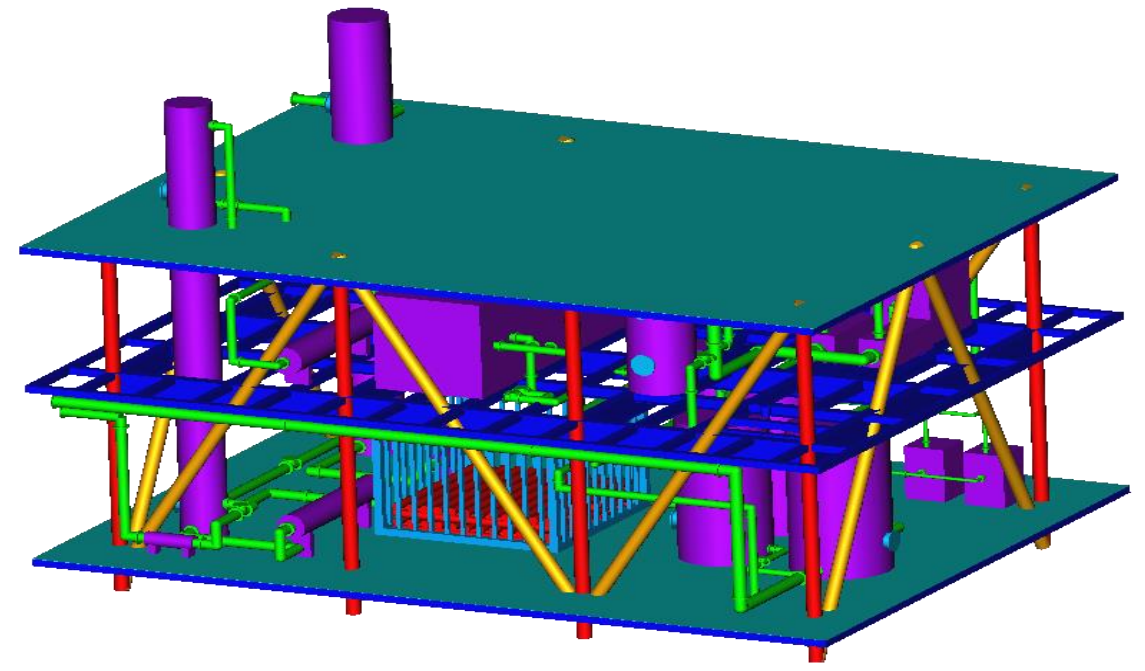

Figure 13 The FLACS CFD model

\subsection{Definition of grids}

All of the grids were defined following the guidelines indicated in Table 7 (FLACS 2015) in association with an acceptable timeframe where modelling criteria and applicability were presented. Grid sizes typically vary with the modelling according to the grid guidelines of the FLACS. Upon application of the guidelines, regular arrays of repeated pipes may be pertinent, e.g., with pipe diameter $\mathrm{D}(0.216 \mathrm{~m})$ and a regular pitch between repeated pipes $\mathrm{P}(0.330 \mathrm{~m})$. Table 8 shows guidelines for the grid definitions in such situations.

Table 7 General guidance on grid (FLACS 2015) 


\begin{tabular}{|l|l|}
\hline $\begin{array}{l}\text { The domain must be included in the explosion and all } \\
\text { targets. }\end{array}$ & Applicable \\
\hline $\begin{array}{l}\text { In the simulation domain where combustion takes place, } \\
\text { grid cells should be uniform, cubical grid cells. }\end{array}$ & Applicable \\
\hline $\begin{array}{l}\text { For the grid embedding process, it is usually acceptable } \\
\text { to have deviations in the aspect of an order of } 10 \% .\end{array}$ & Applicable \\
$\begin{array}{l}\text { However, deviations by a factor of } 2 \text { in the aspect ratio } \\
\text { are not acceptable. }\end{array}$ & The grid size may be larger towards the boundary in all \\
\hline $\begin{array}{l}\text { Tirections. The maximum stretch factor from one cell to } \\
\text { the next is less than or equal to 1.2. }\end{array}$ & Applicable \\
\hline
\end{tabular}

Table 8 Guidance on grid definitions in situations with regular arrays of repeated obstructions with object diameter and a regular pitch between repeated objects (FLACS 2015)

\begin{tabular}{|l|l|}
\hline Criteria & Applicability to the present tests \\
\hline Grid size must be smaller than P. & Grid size must be smaller than $0.330 \mathrm{~m}$. \\
\hline $\begin{array}{l}\text { Grid sizes near pipe diameter D may lead to } \\
\text { turbulence generation that is too low and should be } \\
\text { avoided. }\end{array}$ & $\begin{array}{l}\text { Grid sizes near pipe diameter of } 0.216 \mathrm{~m} \\
\text { should be avoided. }\end{array}$ \\
\hline $\begin{array}{l}\text { The grid resolution of pipe spacing or lower does } \\
\text { not sufficiently resolve the pitch between the pipes. }\end{array}$ & $\begin{array}{l}\text { A grid resolution of } 0.114 \text { m or lower does } \\
\text { not sufficiently resolve the pitch between } \\
\text { the pipes. }\end{array}$ \\
\hline
\end{tabular}

\subsection{Grid sensitivity study in the pipe rack area}

To investigate the grid dependency, a sensitivity study was performed with five different grids. In this study, the number of grid cells was based on the resolution of the high-congestion region or the gas cloud dimension and the minimum dimension of congestion or cloud. Figure 14 presents an example of a schematic design with a grid size of $0.5 \mathrm{~m}$. Table 9 shows a grid size selected in accordance with FLACS 2015 guides. 


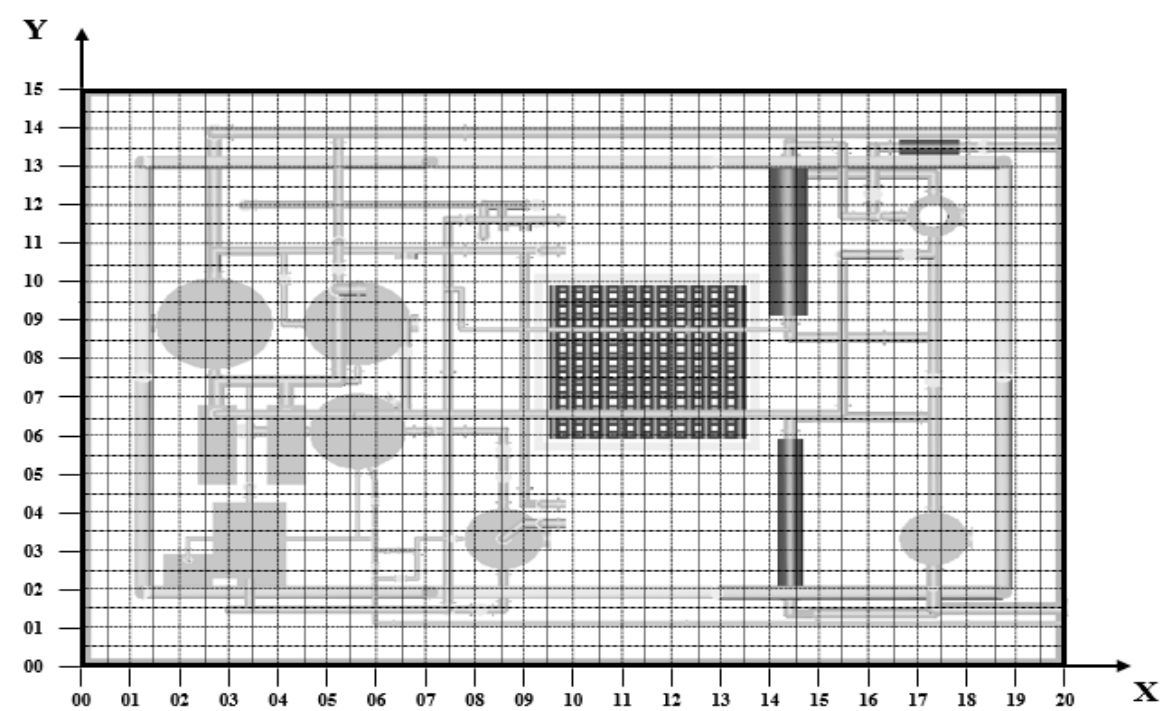

Figure 14 A sample FLACS model with a grid size of $0.5 \mathrm{~m}$

Table 9 The selection of grid size in accordance with the grid guides for situations involving regular arrays of repeated obstructions with object diameter and a regular pitch between repeated objects (FLACS 2015)

\begin{tabular}{|l|c|c|c|c|c|}
\hline \multicolumn{1}{|c|}{ Criteria } & \multicolumn{5}{|c|}{ Grid's applicability (unit: $\mathrm{m}$ ) } \\
\cline { 2 - 6 } & 0.500 & 0.315 & 0.198 & 0.100 & 0.079 \\
\hline $\begin{array}{l}\text { Grid size must be smaller than a pitch size (i.e., } \\
0.330 \mathrm{~m} \text { ). }\end{array}$ & $\mathrm{X}$ & $\mathrm{O}$ & $\mathrm{O}$ & $\mathrm{O}$ & $\mathrm{O}$ \\
\hline $\begin{array}{l}\text { Grid sizes near a pipe diameter (i.e., } 0.216 \mathrm{~m}) \\
\text { should be avoided. }\end{array}$ & $\mathrm{O}$ & $\mathrm{O}$ & $\mathrm{X}$ & $\mathrm{O}$ & $\mathrm{O}$ \\
\hline $\begin{array}{l}\text { The grid resolution of pipe spacing (i.e., 0.114 m) } \\
\text { or lower does not sufficiently resolve the pitch } \\
\text { between the pipes. }\end{array}$ & $\mathrm{O}$ & $\mathrm{O}$ & $\mathrm{O}$ & $\mathrm{X}$ & $\mathrm{X}$ \\
\hline
\end{tabular}

Note: $\mathrm{O}=$ applicable, $\mathrm{X}=$ non-applicable.

According to industry practices, a grid size of $0.5 \mathrm{~m}$ is considered too coarse and one smaller than $0.198 \mathrm{~m}$ is considered too dense. A sensitivity study was performed that varied the grid size in which the overpressure loads were monitored at the locations indicated in Figure 15 with MP50 and MP59 inside the pipe rack; and panel A at the boundary of the pipe rack. Figure 16 shows a typical CFD model with pipes where the grid size is set to be $0.315 \mathrm{~m}$. Figure 17 shows peak overpressure loads at the monitoring points and panel. The sensitivity study revealed that the peak overpressure loads almost reached zero as the grid size became smaller.

For the specific case in the present study, the prediction of the overpressure loads converged at a grid size of $0.198 \mathrm{~m}$. However, it is obvious that zero overpressure loads with a finer grid size made no sense. Rather, the grid size had to be defined by $0.315 \mathrm{~m}$, which gave the largest overpressure loads with pipes. This decision was also made in consultation with the GexCon company in association with their FLACS guidelines, as the FLACS code had been developed to give representative answers for grid cells on scales of 0.1-2 m, and the sub-grid models for turbulence and combustion had not been designed to give convergence, as the scales of a few centimetres or less were refined down. These CFD computations were in reasonably good agreement with the test database. 


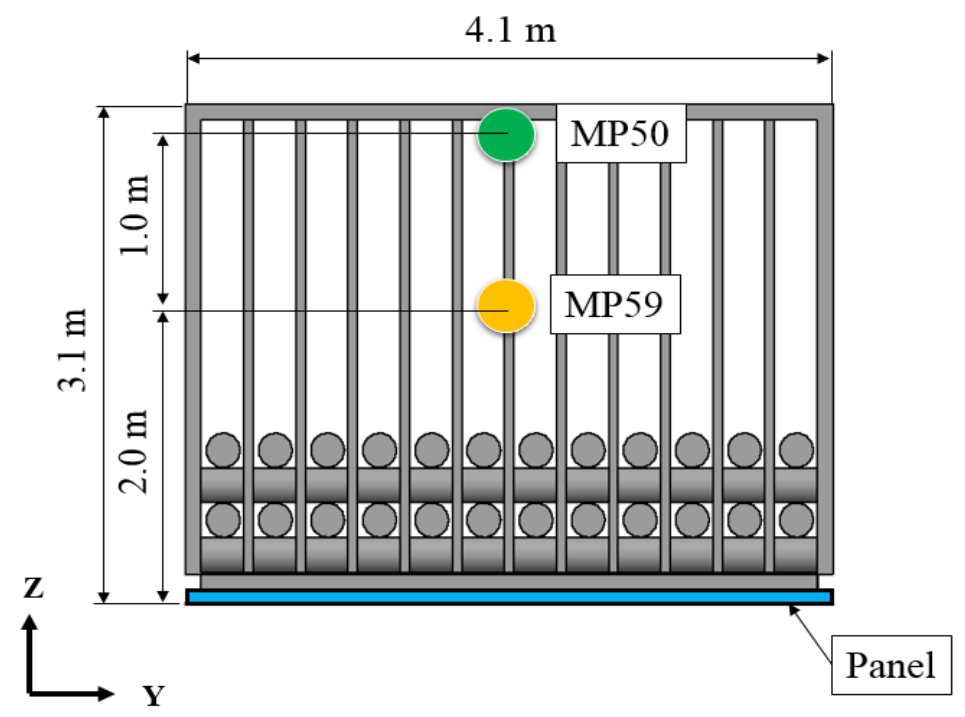

(a) Side view

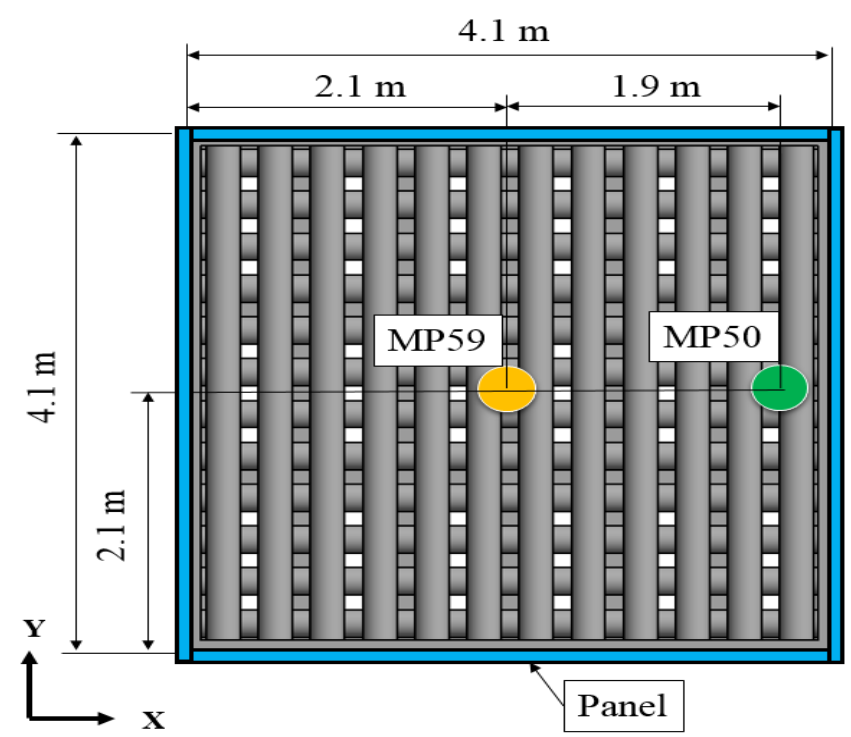

(b) Top view

Figure 15 Locations of monitoring points and panel for the grid sensitivity study 


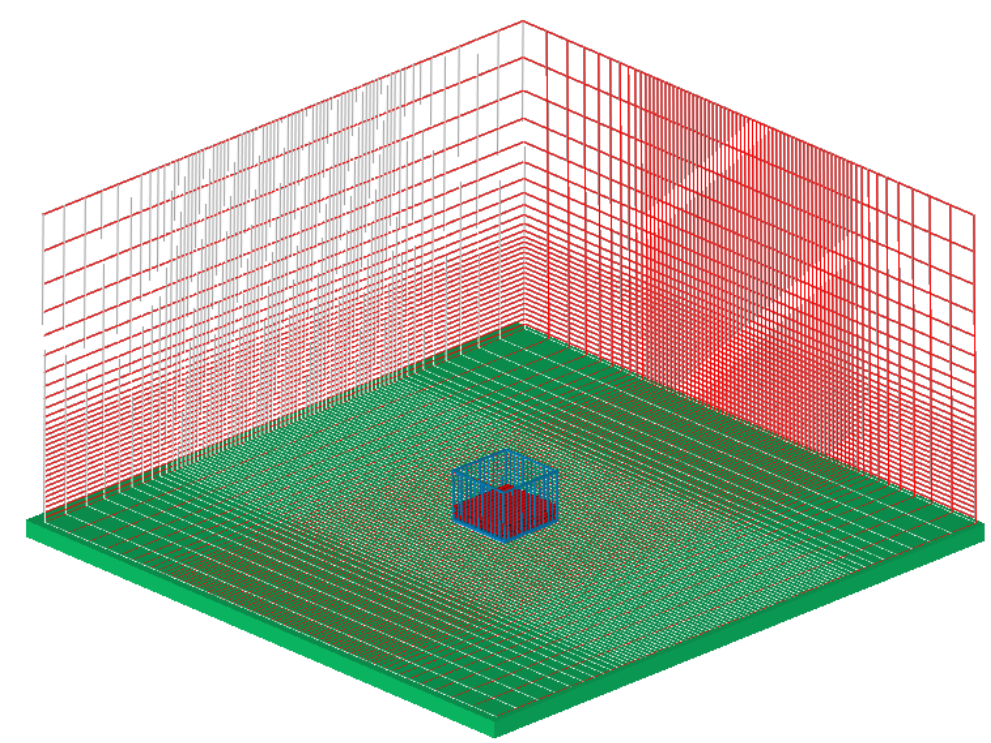

Figure 16 A typical explosion CFD model with pipes for the grid sensitivity study

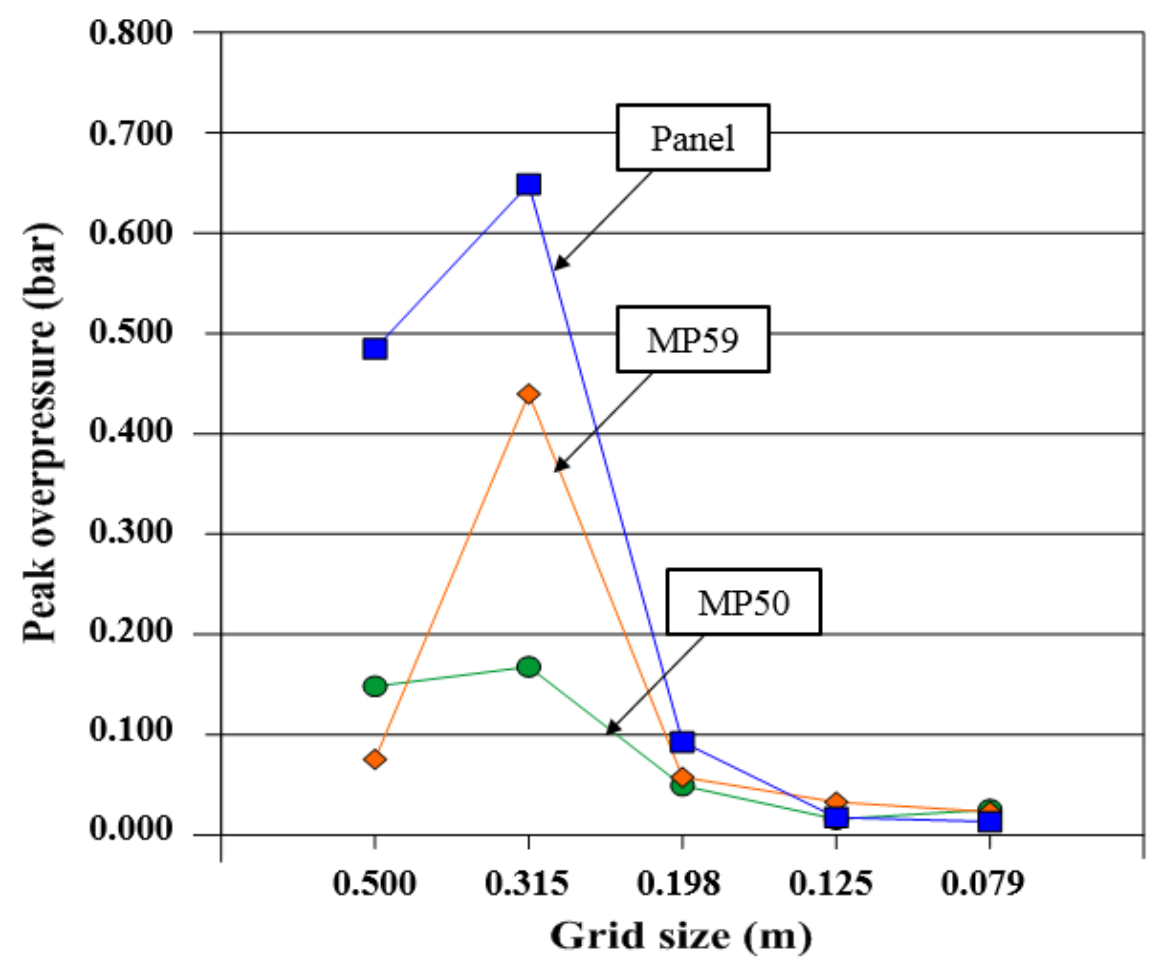

Figure 17 Peak overpressure loads versus grid size with pipe rack

\subsection{Effect of surrounding structures}

The surrounding structures might have also affected the overpressure loads in the explosions. The effect of surrounding obstacles on the overpressure loads was then investigated. The pipe rack alone was compared with the entire module, including the surrounding structures in association with the pipe rack without pipes and with 48 pipes. The $0.315-\mathrm{m}$ grid size was also applied for the surrounding 
structures. Figure 18 shows the models for the pipe rack alone and the full module.

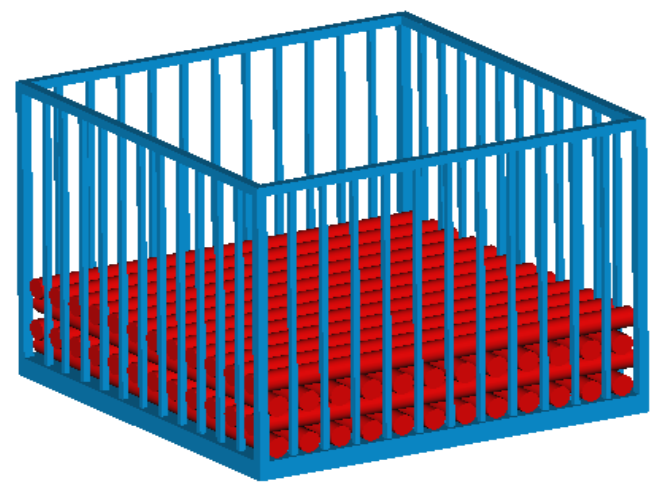

(a) The pipe rack alone model

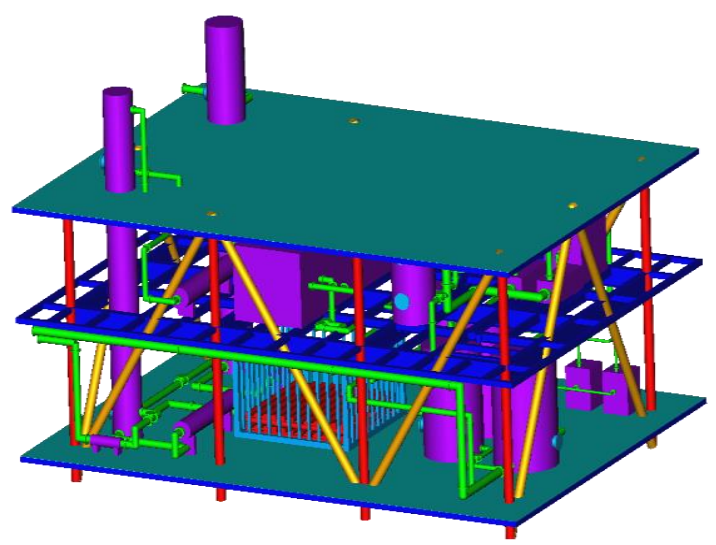

(b) The full module

Figure 18 Models for pipe rack alone and full module

Figures 19 and 20 show the predicted and measured time history of overpressure loads at MP11 or MP13 in association with the pipe rack alone and the full module, respectively. The figures reveal that the surrounding structures increased the overpressure loads. For the positive overpressure loads, the model of the pipe rack alone gave CFD computations close to the test results obtained from the full module. Furthermore, the CFD computations overestimated the overpressure loads compared with the experiment. There are a number of potential reasons for this over-prediction. First, the test results were uncertain because the experiment was not repeated. Second, the vibration that appeared in CFD simulations was not implemented much better than the vibration that appeared in the experiment, as dampening elements such as structural impacts to mitigate vibration were not considered. According to the effect of the vibration, the overpressure loads of the experiment were determined to be lower in value than the overpressure loads of the CFD simulation. To get accurate results of the CFD simulation, it was necessary to consider the dampening elements, vibration and blast wave reflection in the simulation.

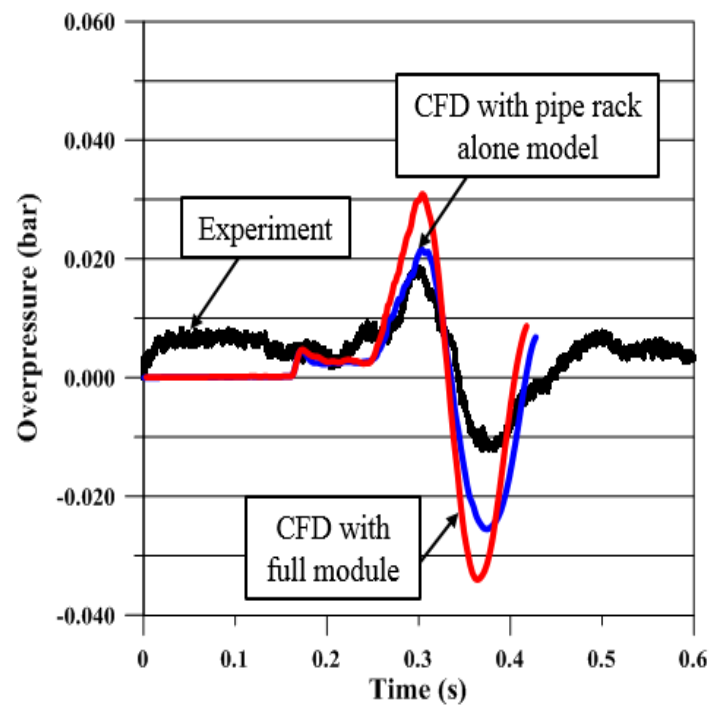

(a) MP11

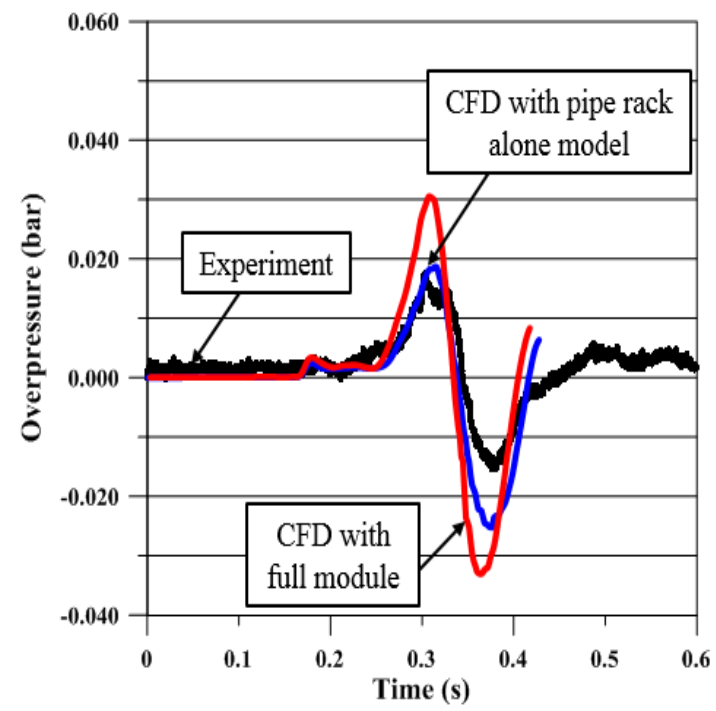

(b) MP13

Figure 19 Overpressure loads-time history for gas cloud only between pipe rack alone and whole module included at monitoring points 


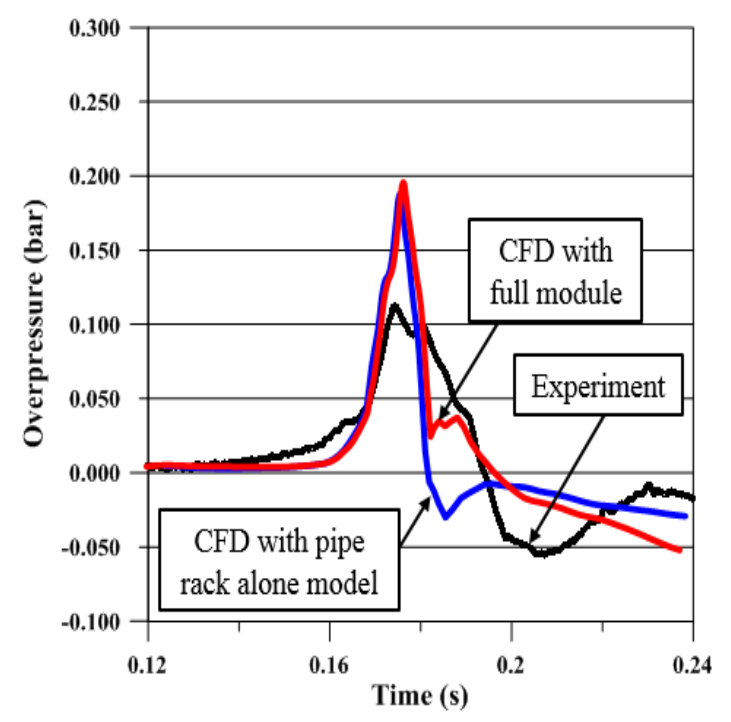

(a) MP11

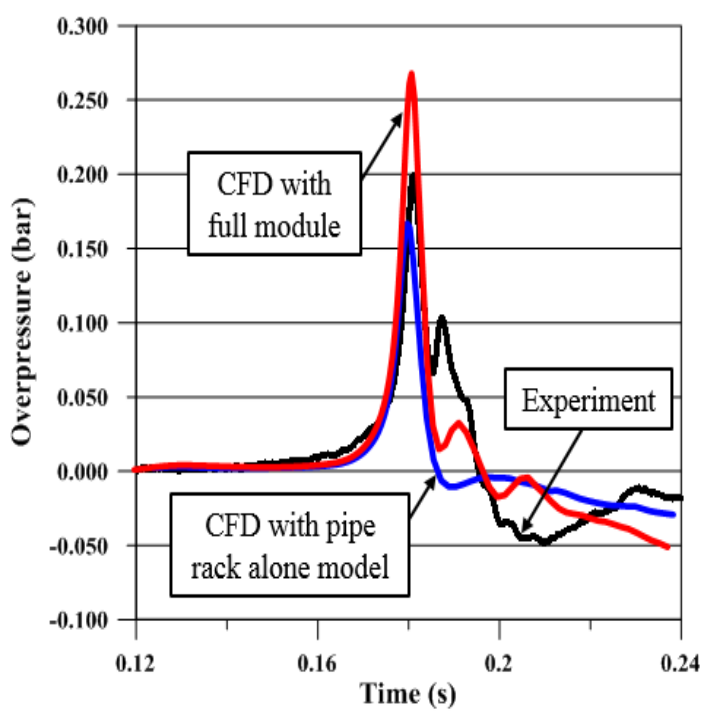

(b) MP13

Figure 20 Overpressure loads-time history for number of pipes 48 between pipe rack alone and full module included at monitoring points

Table 10 Measured and predicted peak overpressure of Case IV (48 pipes)

\begin{tabular}{c|c|c|c|c}
\hline \multirow{2}{*}{$\begin{array}{c}\text { Monitoring } \\
\text { points }\end{array}$} & \multicolumn{3}{|c|}{ Peak overpressure (bar) } & \multirow{2}{*}{$\begin{array}{c}\Delta \mathrm{P}=\text { Exp. - Full } \\
\text { module in FLACS }\end{array}$} \\
\cline { 2 - 4 } MP16 & 0.0356 & 0.1149 & 0.0827 & 0.0793 \\
\hline MP6 & 0.0626 & 0.0740 & 0.0728 & 0.0114 \\
\hline MP9 & 0.0633 & 0.0543 & 0.0656 & 0.0090 \\
\hline MP23 & 0.0714 & 0.0996 & 0.0729 & 0.0282 \\
\hline MP17 & 0.0744 & 0.1957 & 0.1694 & 0.1213 \\
\hline MP7 & 0.0798 & 0.1097 & 0.0788 & 0.0299 \\
\hline MP10 & 0.0801 & 0.0583 & 0.0666 & 0.0218 \\
\hline MP8 & 0.0819 & 0.1259 & 0.0763 & 0.0441 \\
\hline MP24 & 0.0823 & 0.1138 & 0.0706 & 0.0315 \\
\hline MP18 & 0.0910 & 0.1220 & 0.0738 & 0.0310 \\
\hline MP20 & 0.0992 & 0.2199 & 0.1389 & 0.1207 \\
\hline MP11 & 0.1124 & 0.1957 & 0.1874 & 0.0833 \\
\hline MP22 & 0.1458 & 0.2282 & 0.1290 & 0.0824 \\
\hline MP1 & 0.1482 & 0.0820 & 0.0788 & 0.0662 \\
\hline
\end{tabular}




\begin{tabular}{c|c|c|c|c}
\hline MP19 & 0.1588 & 0.1929 & 0.1786 & 0.0342 \\
\hline MP21 & 0.1607 & 0.2496 & 0.1214 & 0.0888 \\
\hline MP15 & 0.1645 & 0.2583 & 0.1462 & 0.0938 \\
\hline MP12 & 0.1666 & 0.2181 & 0.2085 & 0.0516 \\
\hline MP5 & 0.1679 & 0.2223 & 0.1450 & 0.0544 \\
\hline MP4 & 0.1752 & 0.2735 & 0.1517 & 0.0983 \\
\hline MP14 & 0.1920 & 0.2867 & 0.1363 & 0.0947 \\
\hline MP3 & 0.1961 & 0.3022 & 0.1428 & 0.1061 \\
\hline MP13 & 0.1990 & 0.2677 & 0.1668 & 0.0688 \\
\hline MP2 & 0.2233 & 0.2966 & 0.1812 & 0.0732 \\
\hline
\end{tabular}

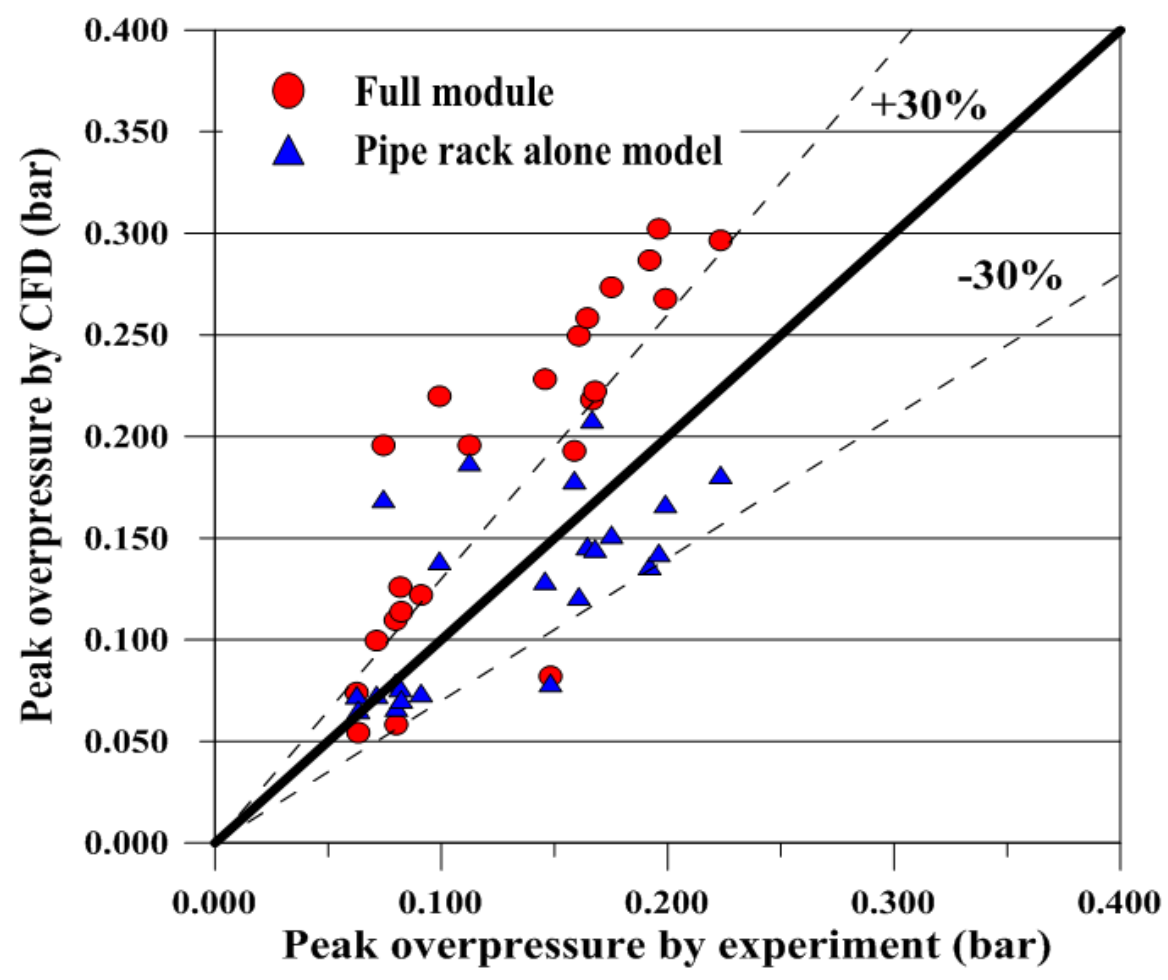

Figure 21 Experimental versus simulation results for peak overpressure for all configurations with $\pm 30 \%$ band

Table 10 lists the peak overpressure loads obtained from the experiment and CFD computations. Figure 21 compares the peak overpressure loads between the experiment and CFD computations with $\mathrm{a} \pm 30 \%$ band. The deviations represent the uncertainty of the computations. The predictions of the full module were $+30 \%$ higher than tests. However, the results for the model of the pipe rack alone were much close to the experiment, although they were under-predicted. The new selection of grid cells for the full module might have required more accurate results. However, it was challenging to adopt grid cells for the full module due to the structural complexity. As such, the grid size determined 
for the model of the pipe rack alone was still applicable for modelling the surrounding structures.

\section{Concluding Remarks}

The objectives of the present study were to investigate the effects of structural congestion and surrounding obstacles on the overpressure loads in hydrocarbon explosions. An experimental and numerical study was undertaken for this purpose. Based on the present study, the following conclusions may be drawn.

1. The effects of structural congestion are not proportional to the structural congestion or the porosity.

2. The peak overpressure loads increase with the increase in structural congestion or with the decrease in porosity.

3. The rise time until the peak overpressure load is reached differs depending on the structural congestion, and it tends to be shorter with increase in the degree of structural congestion.

4. The overpressure loads fall into negative values compared with the ambient pressure and recover to the ambient pressure as the impact energy is released.

5. The peak explosion loads occur in the same location regardless of the structural congestion until the porosity reaches a critical value. This insight may be useful when designing the structural congestion to minimise the peak overpressure loads in explosions.

6. The effect of surrounding structures on the overpressure loads is significant. The overpressure loads with surrounding structures are larger than without.

7. For the specific cases considered in the present study, the CFD computations overestimated the overpressure loads compared with the experiment, regardless of the structural congestion and surrounding obstacles. The CFD computations with the full module generally fell outside the $\pm 30 \%$ band from the test.

8. The CFD computations with the model of the pipe rack alone were closer to the experiment.

9. The CFD computations were significantly affected by the size of the grid cell. Fine grids can lead to unrealistic predicted overpressure loads. In the present study, the grid size was set to be $0.315 \mathrm{~m}$, which gave the largest overpressure loads with pipes.

10. The CFD computations and experiments faced many uncertainties. It is highly desirable to develop a sizable experimental database on a full scale, or at least large-scale test models.

\section{Acknowledgements}

This study was undertaken at the Korea Ship and Offshore Research Institute at Pusan National University which has been a Lloyd's Register Foundation Research Centre of Excellence. Lloyd's Register Foundation (LRF), a UK registered charity and sole stakeholder of Lloyd's Register Group Ltd, invests in science, engineering and technology for public benefit, worldwide.

\section{References}

ABS, 2013. Accidental load analysis and design for offshore structures, American Bureau of Shipping, TX, USA.

Al-Hassan, T. and Johnson, D.M., 1998. Gas explosions in large scale offshore module geometries: Overpressures, mitigation and repeatability, The International Conference on Ocean, Offshore and Arctic Engineering, Lisbon, Portugal.

API, 2006. Design of offshore facilities against fire and blast loading, API-RP2FB, American Petroleum Institute, WA, USA. 
Bauwens, C.R., Chaffee, J. and Dorofeev, S., 2010. Effect of ignition location, vent size, and obstacles on vented explosion overpressures in propane-air mixtures, Comb. Sci. Tech., 182, 1915-1932.

Christou, M. and Konstantinidou, M., 2012. Safety of offshore oil and gas operation: Lessons from past accident analysis, Joint Research Consortium Scientific and Policy Reports, European Commission, Brussels, Belgium.

Czujko, J., 2001. Design of offshore facilities to resist gas explosion hazard - Engineering handbook, CorrOcean ASA, Oslo, Norway.

Czujko, J. and Paik, J.K., 2012a. Hydrocarbon explosion - Assessing and managing hydrocarbon explosion and fire risks in offshore installations, Houston: Marine Technology, SNAME, pp. 23-25.

Czujko, J. and Paik, J.K., 2012b. Paradigm change in safety design against hydrocarbon explosions and fires, FABIG Newsletter, Issue 60, pp. 20-38.

FLACS, 2015. User's manual for Flame Acceleration Simulator (FLACS) version 10.4, GexCon AS, Bergen, Norway.

Hansen, O.R., Hinze, P., Engel, D. and Davis, S., 2010. Using computational fluid dynamics (CFD) for blast wave predictions, Journal of Loss Prevention in the Process Industries, Vol.23, pp. 885-906.

ISO, 2014. Petroleum and natural gas industries - Specific retirements for offshore structures - Part 3: topside structure, ISO 19901-3, International Standards Organization, Geneva, Switzerland.

LR, 2014. Rules and regulations for the classification of offshore units - Guidelines for the calculation of probabilistic explosion loads, Lloyd's Register, London, UK.

Mercx, W. P. M., 1994. Modelling and experimental research into gas explosions, Overall Report of the MERGE Project, CEC contract: STEP-CT-0111 (SSMA).

NORSOK, 2010. Risk and emergency preparedness assessment, NORSOK Standard Z-013, 3rd Edition, Oslo, Norway.

Paik, J.K. and Czujko, J., 2009. Explosion and fire engineering of FPSOs (Phase I): Feasibility study with literature review, Report No. EFEF-01, The Korea Ship and Offshore Research Institute, Pusan National University, Busan, Korea.

Paik, J.K. and Czujko, J., 2010. Explosion and fire engineering of FPSOs (Phase II): Definition of design explosion and fire loads, Report No. EFEF-03, The Korea Ship and Offshore Research Institute, Pusan National University, Busan, Korea.

Paik, J.K. and Czujko, J., 2011. Assessment of hydrocarbon explosion and fire risks in offshore installations: Recent advances and future trends, The IES Journal Part A: Civil \& Structural Engineering, Vol. 4, No. 3, pp. 167-179.

Paik, J.K. and Czujko, J., 2012. Engineering and design disciplines associated with hydrocarbon explosion and fire risks in offshore oil and gas facilities, Transactions of the Society of Naval Architects and Marine Engineers, Vol. 120, pp. 1-39, Washington, DC, USA.

Paik, J.K., Czujko, J., Kim, B.J., Seo, J.K., Ryu, H.S., Ha, Y.C., Janiszewski, P. and Musial, B., 2011. Quantitative assessment of hydrocarbon explosion and fire risks in offshore installations, Marine Structures, Vol. 24, pp. 73-96.

Paik, J.K., Czujko, J., Kim, S.J., Lee, J.C., Kim, B.J., Seo, J.K. and Ha, Y.C., 2014. A new procedure for the nonlinear structural response analysis of offshore installations in explosions. Transactions of the Society of Naval Architects and Marine Engineers, 122, pp. 1-39.

Paik, J.K. and Thayamballi, A.K., 2007. Ship-shaped offshore installations: Design, building, and operation, Cambridge University Press, Cambridge, UK.

Pedersen, H.H. and Middha, P., 2012. Modelling of vented gas explosions in the CFD tool FLACS, Chemical Engineering Transactions, Vol. 26, pp. 357-362.

Selby, C. and Burgan, B., 1998. Blast and fire engineering for topside structures, Phase 2, Final summary report, Steel Construction Institute, UK, Publication number 253.

Spouge, J., 1999. A guide to quantitative risk assessment for offshore installations, DNV Technica, Oslo, Norway.

USCG, 2011. Report of investigation into the circumstances surrounding the explosion, fire, sinking and loss of eleven crew members aboard the mobile offshore drilling unit: Deepwater Horizon, United 
States Cost Guard, ME, USA.

Vinnem, J.E., 2007. Offshore risk assessment - Principles, modelling and application of QRA studies, Springer, Stavanger, Norway. 